\title{
Outlook and challenges for hydrogen storage in nanoporous materials
}

\author{
D. P. Broom ${ }^{1}$ - C. J. Webb ${ }^{2}$ - K. E. Hurst ${ }^{3}$ - P. A. Parilla ${ }^{3}$ T. Gennett ${ }^{3}$. \\ C. M. Brown ${ }^{4,5}$ - R. Zacharia ${ }^{6,7}$ - E. Tylianakis ${ }^{8}$ - E. Klontzas9 ${ }^{9}$ G. E. Froudakis ${ }^{9}$. \\ Th. A. Steriotis ${ }^{10}$ - P. N. Trikalitis ${ }^{9}$ D. L. Anton ${ }^{11}$ - B. Hardy ${ }^{11}$ - D. Tamburello ${ }^{11}$.

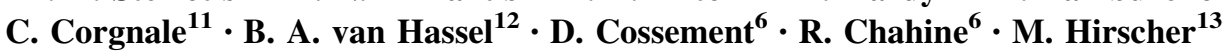

Received: 14 January 2016/ Accepted: 20 January 2016/Published online: 16 February 2016

(C) The Author(s) 2016. This article is published with open access at Springerlink.com

\begin{abstract}
Considerable progress has been made recently in the use of nanoporous materials for hydrogen storage. In this article, the current status of the field and future challenges are discussed, ranging from important open fundamental questions, such as the density and volume of the adsorbed phase and its relationship to overall storage capacity, to the development of new functional materials and complete storage system design. With regard to fundamentals, the use of neutron scattering to study adsorbed $\mathrm{H}_{2}$, suitable adsorption isotherm equations, and the accurate computational modelling and simulation of $\mathrm{H}_{2}$ adsorption are discussed. The new materials covered include flexible metal-organic frameworks, core-shell materials, and porous organic cage compounds. The article concludes with a discussion of the experimental investigation of real adsorptive hydrogen storage tanks, the
\end{abstract}

\footnotetext{
D. P. Broom

dbroom@hidenisochema.com

$\triangle$ M. Hirscher

hirscher@is.mpg.de

1 Hiden Isochema Ltd, 422 Europa Boulevard, Warrington WA5 7TS, UK

2 Queensland Micro- and Nanotechnology Centre, Griffith University, Brisbane, Australia

3 National Renewable Energy Laboratory, 15013 Denver West Parkway, Golden, CO 80401, USA

4 Center for Neutron Research, National Institute of Standards and Technology, Gaithersburg, MD 20899, USA

5 Department of Chemical Engineering, University of Delaware, Newark, DE 19716, USA

6 Institut de Recherche sur l'hydrogène, Université du Québec à Trois-Rivières, P. O. Box 500, Trois-Rivières, QC G9A 5H7, Canada
}

improvement in the thermal conductivity of storage beds, and new storage system concepts and designs.

\section{Introduction}

Solid-state hydrogen storage offers the promise of improving upon the conventional forms of hydrogen storage technology, namely liquid or compressed gas. Liquid $\mathrm{H}_{2}$ storage requires temperatures below $\sim 30 \mathrm{~K}$, while compressed gas storage requires high pressures, up to $70 \mathrm{MPa}$, to achieve practical storage densities. In contrast, the use of hydrogen storage materials can lead to high $\mathrm{H}_{2}$ storage densities well above $30 \mathrm{~K}$ and at lower pressures than those required for compressed gas. The aim of hydrogen storage materials research is thus to develop an

7 Gas Processing Center, College of Engineering, Qatar University, P. O. Box 2713, Doha, Qatar

8 Department of Materials Science and Technology, University of Crete, P. O. Box 2208, 71003 Heraklion, Crete, Greece

9 Department of Chemistry, University of Crete, P. O. Box 2208, 71003 Heraklion, Crete, Greece

10 Institute of Nanoscience and Nanotechnology, NCSR "DEMOKRITOS", Aghia Paraskevi Attikis, 15310 Athens, Greece

11 Savannah River National Laboratory, Aiken, SC 29808, USA

12 United Technologies Research Center, 411 Silver Lane, East Hartford, CT 06118, USA

13 Max-Planck-Institut für Intelligente Systeme, Heisenbergstrasse 3, 70569 Stuttgart, Germany 
effective $\mathrm{H}_{2}$ storage method that can operate at near-ambient temperatures and at pressures below $10 \mathrm{MPa}$.

The materials currently being considered can be generally separated into hydrides and nanoporous materials $[1$, 2], the latter of which physically adsorb hydrogen molecules $\left(\mathrm{H}_{2}\right)$ on their surface via van der Waals and electrostatic forces. Nanoporous materials have several advantages. For example, the adsorption process is completely reversible and the kinetics of adsorption are rapid $[3,4]$, in contrast to hydrogen absorption by many metal and complex hydrides. The low enthalpy of adsorption also reduces thermal management issues. Together with its reversibility, the physical adsorption of $\mathrm{H}_{2}$ does not typically induce crystallographic phase changes in the host material; so material stability during repeated cycling of hydrogen is less of an issue.

On the other hand, the use of adsorption has drawbacks. For example, the physical interaction of $\mathrm{H}_{2}$ with solid surfaces is quite weak because $\mathrm{H}_{2}$ has no charge and no dipole moment, a relatively weak quadrupole moment, and a low polarisability [5, 6]. High storage capacities can thus only be achieved at low temperatures. Furthermore, the physical adsorption of $\mathrm{H}_{2}$ is a surface process, so the advantage of the presence of a nanoporous material in a tank is provided only by the enhanced density of the adsorbed $\mathrm{H}_{2}$ in the pores. This limits volumetric storage densities, regardless of the impressive gravimetric capacities reported recently for some novel adsorbents $[7,8]$.

Nevertheless, significant advances have been made in the synthesis of new adsorbents with very high surface areas, and hence adsorption capacities, including metalorganic frameworks (MOFs), covalent organic frameworks (COFs), amorphous organic polymers, and novel types of porous carbon. Figure 1, for example, shows the trend of increasing gravimetric storage capacity with increasing BET surface area for MOFs, with the best performing zeolites and activated carbons included for comparison.

Nanoporous materials thus remain competitive, although overcoming some of the problems identified above will involve significant materials research and engineering challenges. However, it is worth noting that porous adsorbents such as zeolites, silica gels, activated aluminas, activated carbons, and carbon molecular sieves have been used industrially in vast quantities for decades, in many applications, including gas, vapour and liquid phase separations, and catalysis, so their economic and practical viability is proven. The main challenge in adsorptive hydrogen storage research has thus been the development of new adsorbents that share this viability while also showing sufficiently high hydrogen storage capacities for practical use.

In this article, the current status of the field is discussed and existing challenges are identified. Initially, the

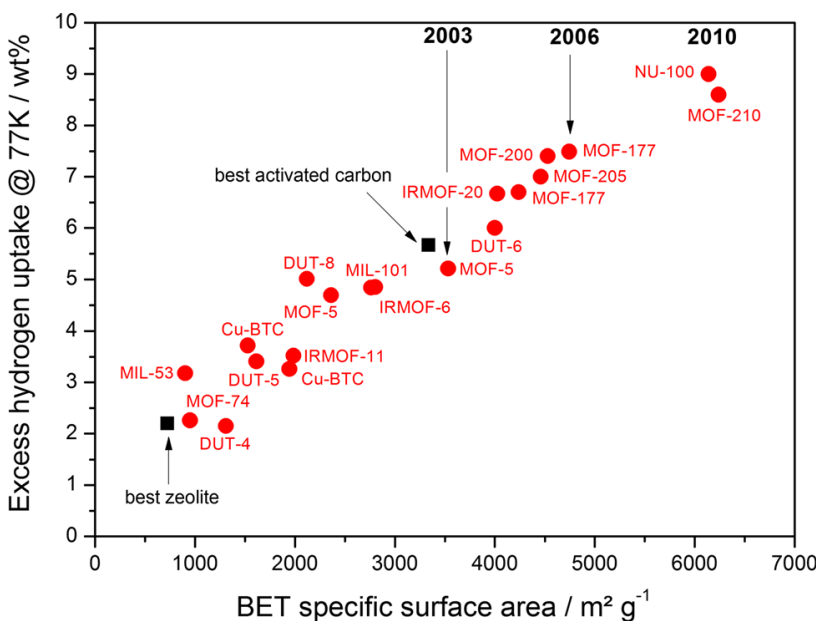

Fig. 1 A plot of excess gravimetric hydrogen adsorption capacity at $77 \mathrm{~K}$ (at $2 \mathrm{MPa}$ or above) versus BET specific surface area for a range of metal-organic frameworks measured in different laboratories, hence the inclusion of two values for $\mathrm{Cu}-\mathrm{BTC}, \mathrm{MOF}-5$, and MOF-177 (modified and updated from [7])

measurement of $\mathrm{H}_{2}$ adsorption is addressed, including the question of the adsorbed phase density and volume, and the use of neutron scattering to study adsorbed $\mathrm{H}_{2}$. Suitable adsorption isotherm equations and the accurate computational modelling and simulation of $\mathrm{H}_{2}$ adsorption by nanoporous materials are then addressed. Some of the interesting new materials that are being developed are then identified, and the development of practical storage tanks is examined.

\section{Measurement}

The measurement of $\mathrm{H}_{2}$ adsorption is essential in order to characterise the hydrogen storage potential of nanoporous materials, while gaining a better understanding of the behaviour of the adsorbed $\mathrm{H}_{2}$ in different materials is critical to the development of improved adsorbents. In this section, the measurement techniques, the properties of the adsorbed $\mathrm{H}_{2}$ phase, and the study of adsorbed $\mathrm{H}_{2}$ using neutrons are discussed.

\section{1 $\mathrm{H}_{2}$ adsorption measurement techniques}

The amount of $\mathrm{H}_{2}$ adsorbed is typically measured using either the manometric or gravimetric techniques. In the manometric case, known amounts of $\mathrm{H}_{2}$ are prepared and introduced to the sample cell step-by-step, using measurements of pressure, temperature, and volume, and an equation of state for $\mathrm{H}_{2}$, to calculate the amount of adsorption (see Fig. 2a). At each point, the amount of $\mathrm{H}_{2}$ in the gas phase is calculated and any missing $\mathrm{H}_{2}$ is attributed to the adsorbed phase. In order to determine the number of 
(a)

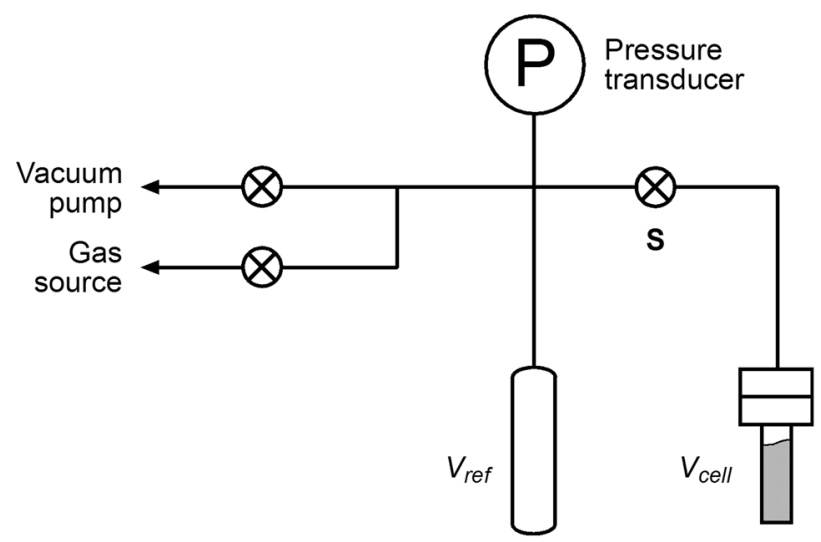

(b)

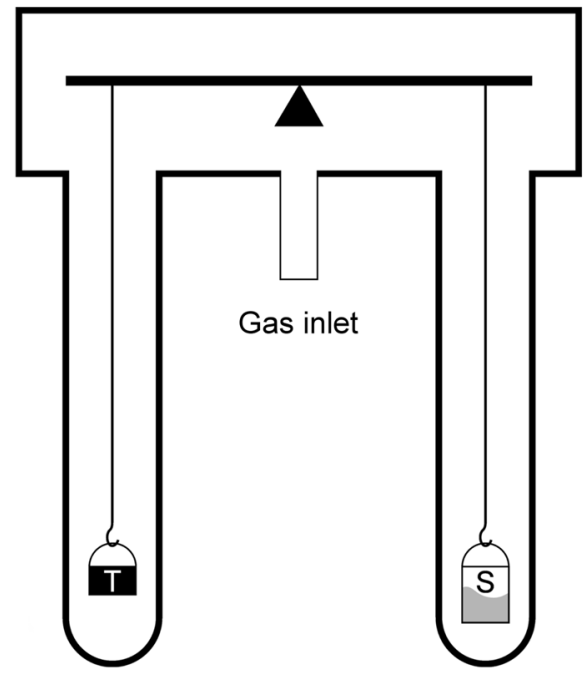

Fig. 2 Schematic diagrams of a a simplified manometric apparatus [9] and b gravimetric apparatus employing a symmetric microbalance with both the sample (S) and the tare weight (T) suspended in the gas [11]. (Reprinted from International Journal of Hydrogen Energy, 39(1), C. J. Webb, E. M. Gray, Analysis of the uncertainties in gas

moles in the gas phase, however, the accessible volume must be known. This void or dead volume is the difference between the volume of the empty sample cell and the volume occupied by the sample and the adsorbate. Determination of the combined sample and adsorbate volume is intrinsically problematic $[9,10]$ and can be further complicated by sample swelling.

The gravimetric technique, on the other hand, directly determines the amount adsorbed from the weight measured by a microbalance (see Fig. 2b). In this case, the amount of gas introduced does not need to be calculated, and the error accumulation associated with the manometric method is also avoided [11]. However, the microbalance reading must be corrected for the buoyancy effect of the sample in the surrounding fluid (gas) [12], for which knowledge of the volume of the sample and the adsorbate is required, in a directly analogous way to the manometric method.

Both techniques have advantages and disadvantages [2], but both rely on the determination of the volume of the sample and the adsorbed phase in order to calculate the absolute adsorption or capacity. For materials amenable to helium pycnometry, this reduces to the problem of knowing the volume of the adsorbate as a function of temperature, pressure, and uptake.

If the adsorbate volume, $V_{\mathrm{ad}}$, is ignored in the manometric calculations mentioned above, i.e. it is assumed that $V_{\mathrm{ad}}=0$, and the two techniques use only the sample volume in the calculation of the adsorbed quantity, then the uptake is underestimated by the amount of gas that would uptake measurements using the Sieverts method, 366-375, Copyright (2014), and 39(13), C. J. Webb, E. M. Gray, Analysis of uncertainties in gas uptake measurements using the gravimetric method, 7158-7164, Copyright (2014), with permission from Elsevier)

occupy $V_{\text {ad. }}$. The calculated quantity is then known as the excess adsorption or capacity.

Although both techniques are conceptually simple, the results obtained on identical samples in different laboratories by Zlotea et al. [13] give cause for alarm about their accuracy and reproducibility. Several laboratories were sent the same carbon molecular sieve with sample preparation instructions [13]. It can be seen in Fig. 3 that the reported results showed considerable disparity, particularly at higher pressure, so this remains a significant challenge for the characterisation of $\mathrm{H}_{2}$ adsorption by nanoporous materials. It should be noted, however, that the results from a more recent exercise demonstrated better agreement [14].

\subsection{Capacity definitions}

The capacity is a measure of how much $\mathrm{H}_{2}$ is stored by a material. It can be normalised gravimetrically (the amount stored on a mass basis) or volumetrically (the amount stored in a given volume). However, in the literature, hydrogen storage capacities are often reported without proper definition or sufficient experimental details. For example, the terms absolute and total, with regard to adsorbed quantities and capacities, are sometimes used interchangeably $[2,15,16]$. This variation in definitions can cause confusion and lead to unrealistic capacity claims.

The common types of capacity are the excess, $n_{\mathrm{ex}}$, i.e. the amount of gas present over and beyond the amount of a non-adsorbing non-interacting gas under the same 


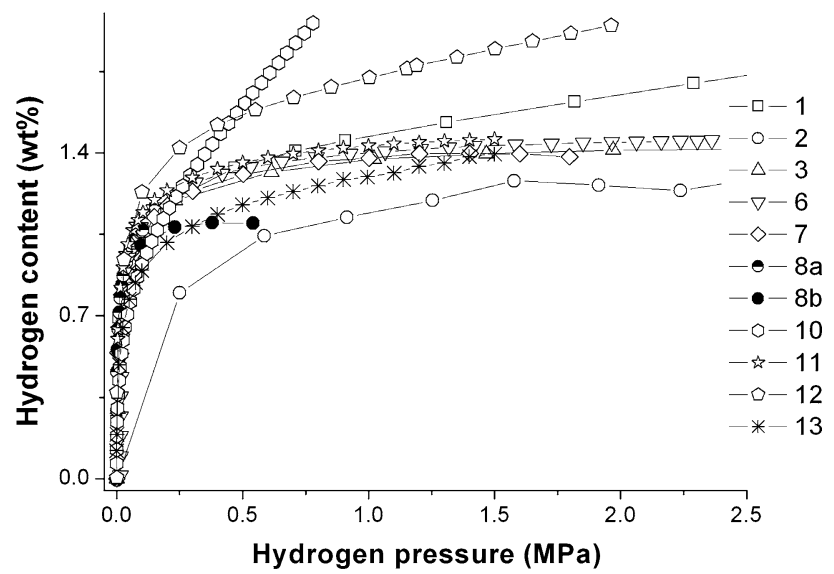

Fig. $3 \mathrm{H}_{2}$ adsorption isotherms measured at $77 \mathrm{~K}$ on a carbon molecular sieve by eleven interlaboratory test exercise participants, plotted to 2.5 MPa [13]. (Reprinted from International Journal of Hydrogen Energy, 34(7), C. Zlotea, P. Moretto, T. Steriotis, A Round Robin characterisation of the hydrogen sorption properties of a carbon based material, 3044-3057, Copyright (2009), with permission from Elsevier)

conditions of pressure and temperature, the absolute, $n_{\mathrm{abs}}$, the quantity of gas molecules in the adsorption volume, $V_{\mathrm{ad}}$ (defined as the volume where the density of the adsorbate differs from the free gas density through gas-solid interactions), and the total, $n_{\text {tot }}$, the quantity of gas molecules associated with the sample in both the free and adsorbed state. The gas molecules that are associated with the sample are determined by defining an appropriate volume, such as the bulk volume of the material.

An alternative to the standard definitions above is the net adsorption (or net capacity). This is defined as the amount of $\mathrm{H}_{2}$ in the volume containing the adsorbent minus the amount of $\mathrm{H}_{2}$ in the same volume, without the adsorbent, at an identical temperature and pressure [17]. This simply uses a different reference point for the calculation. It has the advantage that the volume of the adsorbent does not need to be known. It also provides a direct measure of the benefit of filling the tank with adsorbent, in comparison with pure gas compression, with the peak in the net adsorbed quantity indicating the optimum storage pressure, in this respect [18]. However, the use of the net adsorption is yet to be widely adopted.

In hydrogen storage studies, $n_{\mathrm{ex}}$ is often reported as the amount adsorbed, but in other cases, $n_{\mathrm{abs}}$ or $n_{\mathrm{tot}}$ is reported instead. It is important, however, to clearly state the quantity being reported and explicitly define the assumptions used to calculate the capacities. The volume, $V_{\mathrm{ad}}$, of a gas adsorbed on an adsorbent has been a topic of considerable discussion because of its direct relevance to the determination of $n_{\text {abs }}$. In addition, isotherm models, which we cover in Sect. 2.3, conventionally describe $n_{\text {abs }}$ and thus require the determination of $V_{\text {ad }}$ to compare theory with experiment. The adsorbed phase can range from a simple homogenous monolayer on a well-defined surface, to a complex mix of adsorbate-adsorbent interactions on a heterogeneous material, with pores of varying size and geometry, in the presence of different surface functionalities. Therefore, in complex systems, the resultant adsorbate-adsorbent interactions can vary not only as a function of pressure and temperature, but also by location. In the context of investigating new adsorbents, this translates to an ill-defined $V_{\text {ad }}$ that makes $n_{\text {abs }}$ difficult to quantify. The volume of the sample itself may also be difficult to accurately quantify throughout the sorption experiment. Although the calculation of $n_{\text {tot }}$ can involve a well-defined volume, the densification of the sample can drastically influence this volume and the hydrogen storage properties. Therefore, these methods must be explicitly reported as the densification could alter the physical structure of pore volume and interparticle void space.

It is possible to calculate $n_{\mathrm{abs}}$ from $n_{\mathrm{ex}}$ with an additional assumption. The two main options are to assume that either the volume occupied by the adsorbed $\mathrm{H}_{2}, V_{\mathrm{ad}}$, or its average density, $\rho_{\mathrm{av}}$, is known [2, 8, 19]. For a purely microporous adsorbent, for example, $V_{\mathrm{ad}}$ can be assumed to be equal to the pore volume, $V_{\text {pore }}$ [18]. Therefore, $n_{\mathrm{ex}}$ can be converted to $n_{\mathrm{abs}}$ using the following expression [8, 18],

$n_{\mathrm{abs}}=n_{\mathrm{ex}}+V_{\text {pore }} \rho_{\mathrm{fg}}$

where $\rho_{\text {fg }}$ is the free gas density. Note that at low pressures the difference between $n_{\mathrm{ex}}$ and $n_{\mathrm{abs}}$ tends to be minimal, particularly when there is a significant amount of adsorption, as the $V_{\text {pore }} \rho_{\text {fg }}$ term can be insignificant compared to $n_{\text {ex }}$.

Alternatively, the density of the adsorbed $\mathrm{H}_{2}, \rho_{\mathrm{ad}}$, can be assumed to be represented by an average value, $\rho_{\mathrm{av}}[2,8$, 19]. In this case, $n_{\mathrm{abs}}$ is given by,

$n_{\mathrm{abs}}=\frac{n_{\mathrm{ex}}}{\left(1-\frac{\rho_{\mathrm{fg}}}{\rho_{\mathrm{av}}}\right)}$.

Unfortunately, neither $V_{\text {ad }}$ nor $\rho_{\text {ad }}$ is known and they are difficult to measure. Furthermore, the properties of the adsorbed $\mathrm{H}_{2}$ are dependent on a number of factors, particularly in real, heterogeneous materials [20], and those with pores of varying size and geometry.

An additional concern that can lead to measurement error is the use of helium to determine the skeletal volume of the sample needed for the determination of $n_{\mathrm{ex}}$. This assumes that at an appropriate temperature and pressure helium does not adsorb and that it can access the same volume as $\mathrm{H}_{2}$. The problem with this approach is that neither assumption is likely to be entirely satisfied in nanoporous materials [8, 21]. This remains a significant challenge for the accurate measurement of $\mathrm{H}_{2}$ adsorption. 
To conclude, only the standard capacity definitions defined above [22-24] should be used, while investigation of the use of net adsorption more widely would be an interesting topic for future research. In general, it may be advantageous to report several of the capacity types to make the comparison between materials easier. Furthermore, it can be argued that while absolute adsorption is required for the direct fitting of isotherm equations and for the determination of the enthalpy or heat of adsorption [25], it is best avoided for the sole metric for comparison of the hydrogen storage performance of different materials. Finally, for a thorough comparison of different measurements, it is recommended to report all assumptions involved in calculating the capacity values (excess, absolute, total, and net) [24].

\subsection{Neutron scattering}

Microscopic information regarding the behaviour of $\mathrm{H}_{2}$ at an atomic or molecular level can be obtained using neutron scattering techniques [26]; neutron diffraction, in particular, has widely been used to study $\mathrm{D}_{2}$ adsorbed in porous materials [27-30]. Difficulties arise from the large incoherent scattering cross section of $\mathrm{H}_{2}$ that makes the static structure factor, $S(Q)$, difficult to determine from the resultant background. Standard diffraction techniques are also most helpful if the $\mathrm{H}_{2}$ or $\mathrm{D}_{2}$ is adsorbed in a structurally periodic manner. Other methodologies are better suited to the study of disordered fluid-like phases, including liquid diffraction or extrapolation from the kinematically accessible range of the fully dynamic structure factor, $S(Q, \omega)$ [28]. Indeed, inelastic neutron scattering (INS) has widely been applied to probe the potential energy surface experienced by $\mathrm{H}_{2}$ and to gain insight into $\mathrm{H}_{2}$ weakly adsorbed in various carbons [29-31] and MOFs [32, 33], and in the more strongly bound electrostatic environments found in zeolites [34, 35] and Kubas-type inorganic compounds [36]. Furthermore, quasi-elastic neutron scattering (QENS) can be used to determine the dynamics of $\mathrm{H}_{2}$ molecules adsorbed in nanoporous materials by analysing the broadening, in energy, of the elastic scattering peak [37-39]. Both INS and QENS, in contrast to diffraction, can exploit the large incoherent scattering cross section of $\mathrm{H}_{2}$.

Neutron diffraction is still typically performed using $\mathrm{D}_{2}$ to reduce the incoherent scattering from $\mathrm{H}_{2}$. This isotopic substitution can affect the physics due to differences in zero point energy, as evidenced by differences in the thermodynamic properties [40-42]. Few studies detail the structural differences between $\mathrm{H}_{2}$ and $\mathrm{D}_{2}$ adsorption; however, with the advent of high-intensity neutron sources and diffraction instruments, this may change. The negative consequences of the incoherent background may be overestimated since most published neutron diffraction work on hydrogen-containing MOFs does not rely on deuterated MOF ligands, even though $\mathrm{D}_{2}$ is subsequently used to determine their binding characteristics [43-47]. Several hydrogen-containing structures are also well known from powder diffraction [48]. Early evidence suggests there is little distinction between the structural parameters derived from the weak coherent scattering of $\mathrm{H}_{2}$ compared to the strongly coherent scattering of $\mathrm{D}_{2}$ adsorbed in one particular MOF, in which the centre of the $\mathrm{H}_{2}$ nuclear scattering density was found to be $2.26(4) \AA$ from the metal atom compared to a $\mathrm{D}_{2}$ distance of 2.23(5) $\AA$; however, the broader impact of this is yet to be thoroughly evaluated [49].

Most measurements are also currently made at liquid helium temperatures, where the thermal motion and diffusion of weakly bound molecules is minimal. Barriers remain to performing detailed measurements on adsorptive systems over desired in situ operational temperature and pressure ranges, although the practical aspects of performing experiments under these conditions are not difficult to overcome at a neutron source $[39,50,51]$. Another consideration is the trade-off in neutron intensity versus data resolution. Higher accuracy structural information requires a higher-resolution diffractometer, which typically provides a lower count rate. This is mitigated somewhat at spallation neutron sources compared to reactor sources, and the situation will likely improve further with global development of higher-intensity neutron sources. Some fast diffractometers can currently perform this type of work, even if the results provide limited structural information, as evidenced by the report of negative thermal expansion and site occupation factors as a function of temperature for $\mathrm{D}_{2}$ in a specific MOF that indicates $\mathrm{D}_{2}$ retention even above $100 \mathrm{~K}$ [47]. The low temperature requirements of the scattering technique might also be mitigated by materials that adsorb $\mathrm{H}_{2}$ at higher temperatures, as required for $\mathrm{H}_{2}$ storage. In this case, the enthalpy of $\mathrm{H}_{2}$ adsorption would presumably be large enough for molecules to remain bound at higher temperatures, thus permitting structural characterisation over a wider temperature range.

Neutron total scattering or pair distribution measurements are an alternative for studying more fluid-like adsorbate phases. This technique additionally incorporates the short-range order present in the background of diffraction data [52]. Methodologies to deal with incoherent scattering backgrounds are being developed [53] and, while unlikely to allow extensive study of $\mathrm{H}_{2}$ adsorption on structures that are poorly defined crystallographically, may be useful to study MOFs with H-containing ligands.

Many assumptions used to analyse macroscopic gas adsorption data rely on the knowledge of the adsorbed phase volume or density, as discussed in Sect. 2.2, for 
which independent measurements are difficult or impossible. For complex pore networks, attempts have been made to characterise and reconcile pore structures obtained from small-angle scattering data with those from adsorption/intrusion studies (e.g. [54]). However, the data are complicated by the multiple length-scales, closed porosity, and surface roughness factors that inhibit a unique description and depend upon the adsorption models used (see [55, 56], for example). With the advent of MOFs that are crystallographically well defined, and the observation that the adsorbed $\mathrm{D}_{2} / \mathrm{H}_{2}$ phases can be characterised in a precise crystallographic manner, it is likely that a robust link between assumptions in traditional gas adsorption techniques and independent observation can be achieved, particularly in the case of the heterogeneous adsorption potentials exhibited by unsaturated metals in MOFs. Using high-resolution diffraction, and quantification of the porefilling for other adsorbates, such as $\mathrm{N}_{2}$ (typically used for surface area determination) and $\mathrm{D}_{2}$ in MOFs, it should be possible to obtain a real space view of the gas adsorption process at $77 \mathrm{~K}$ and thus extract meaningful parameters corresponding to estimated molecular size and adsorbed phase density. Judicious choice of the pore structure to be studied in a series of MOFs would allow the effects of confinement and dimensionality of the pore and adsorbateadsorbate interactions on curved surfaces to be interrogated in detail.

\section{Modelling}

In order to gain further insight into the $\mathrm{H}_{2}$ adsorption process, to provide data for the design of full storage systems, and to screen materials for practical applications, various modelling and simulation techniques can be used. In this section, the fitting of macroscopic $\mathrm{H}_{2}$ adsorption data to analytical isotherm equations and the use of molecular-level computational methods are discussed.

\section{1 $\mathrm{H}_{2}$ adsorption isotherm modelling}

Experimental $\mathrm{H}_{2}$ adsorption isotherm data can be described by theoretical models through the adjustment of their parameters using, for example, least squares minimisation [57, 58]. This fitting process allows the prediction of thermodynamic properties, such as the excess adsorption and isosteric enthalpies, over a wide range of temperatures and pressures [59] and can provide an estimate of parameters such as the adsorbed phase volume, saturation pressure, and limiting adsorption capacity, which are otherwise difficult to determine [59, 60]. Isotherm fitting can also provide insight into underlying adsorption mechanisms and the pore structure characteristics of adsorbents [60, 61], while data needed for the modelling and design of hydrogen storage systems can also be obtained [62-67].

Various models are available [20, 68], from simple expressions, such as the Langmuir and Freundlich equations, to those of greater complexity, which include the Tóth [69], Unilan [61, 70], modified Dubinin-Astakhov (DA) [59] models, and the multicomponent potential theory of adsorption (MPTA) [60, 71]. Different assumptions are used; for example, the Langmuir equation describes adsorption on energetically homogeneous surfaces. Each site is occupied by only one molecule, with no adsorbateadsorbate interactions. The Unilan model uses the Langmuir equation, but accounts for heterogeneity using a uniform distribution of adsorption site energies, while the modified DA model is based on Dubinin's theory of volume filling of micropores [72]. It thus assumes that adsorption occurs due to a Polanyi-type adsorption potential that is present throughout the pore volume, so adsorption occurs via pore volume filling rather than the monolayer formation assumed in the Langmuir model [68].

The simpler models can fit data for a wide range of traditional adsorbents over limited ranges of pressure and allow the transformation of measured isotherms into linear forms from which model parameters can easily be obtained using linear regression [68]. However, due to deviation of the predictions by the simpler models for data measured over wide pressure ranges [68] and the lack of temperature dependence, as required in realistic adsorptive storage systems, more rigorous adsorption models, such as the modified DA, Unilan, and MPTA approaches, tend to be favoured by hydrogen storage system developers.

Dundar et al. [73] recently found that different models were needed to fit data for different MOFs. The modified DA, Unilan, and MPTA models were used to fit experimental $\mathrm{H}_{2}$ adsorption isotherms for three prototypical materials (MOF-5, Cu-BTC, and MIL-101) at different temperatures. Isotherms for $\mathrm{Cu}-\mathrm{BTC}$ and $\mathrm{MIL}-101$ were better described using the modified DA model, while $\mathrm{H}_{2}$ adsorption on MOF-5 was better described by the Unilan and Tóth models. The fits for MOF-5 data, measured and reported by Zhou et al. [74], in the temperature range 77-300 K, are shown in Fig. 4 [73]. The use of the modified DA model to fit $\mathrm{H}_{2}$ adsorption isotherms for MOF-5 was also examined by Purewal et al. [61]. It produced a well-behaved fit, but the predicted isotherms deviated from experimental data between 200 and $300 \mathrm{~K}$, resulting in anomalous negative adsorption. The results also predicted unusually large saturation pressures, free energies of adsorption, and heterogeneity parameters. However, the model better described $\mathrm{H}_{2}$ adsorption data for Maxsorb and Cu-BTC [61].

Although both the Unilan and Tóth models outperform the modified DA model when used to fit data for MOF-5, 
(a)

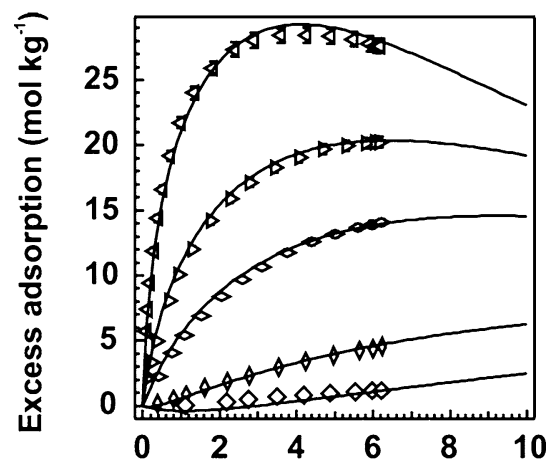

(b)

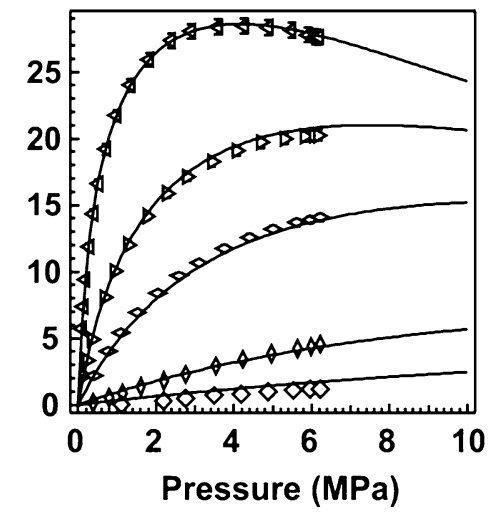

(c)

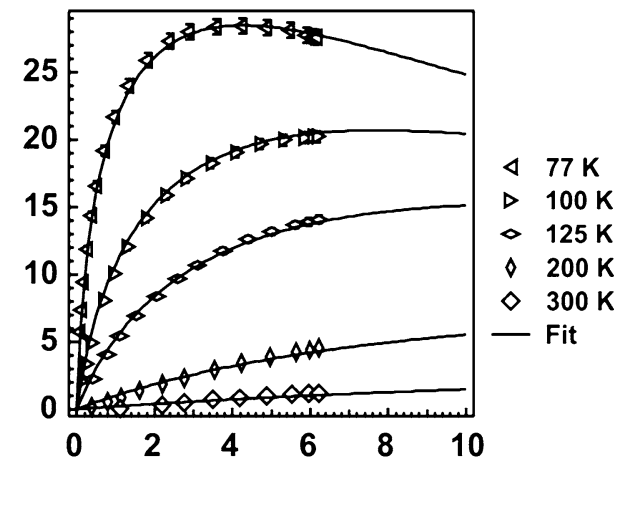

Fig. 4 Plots showing the fits to experimental $\mathrm{H}_{2}$ adsorption isotherms for MOF-5 [73], measured in the temperature range $77-300 \mathrm{~K}$ by Zhou et al. [74], using the a Unilan, b modified DA, and c MPTA models. (Reprinted from Fluid Phase Equilibria, 363, E. Dundar, R.
Zacharia, R. Chahine, P. Bénard, Performance comparison of adsorption isotherm models for supercritical hydrogen sorption on MOFs, 74-85, Copyright (2014), with permission from Elsevier)

of experiments. Computational methods, however, can predict macroscopic adsorption properties and thus offer an efficient alternative. They can also help design better adsorbents by providing insight into structure-property relationships and can yield molecular-level information that is otherwise inaccessible. Adsorption-based $\mathrm{H}_{2}$ storage studies most commonly involve grand canonical Monte Carlo (GCMC) simulation and quantum chemical (QC) calculations.

\subsubsection{Grand canonical Monte Carlo (GCMC) simulations}

GCMC simulations can be used to determine both adsorption isotherms and isosteric enthalpies of adsorption since they imitate experiment [76-78]. The results- the number of particles, $N$, in a model porous solid versus the external chemical potential, $\mu$, at a temperature, $T$-are directly comparable to the output of adsorption experiments, although simulations calculate the total amount of adsorbate in the pores, whereas experiments measure the excess (see Sect. 2.2). Apart from technicalities, including the size of the simulation box, choice of periodic boundary conditions, and the number of iterations, the quality of a GCMC simulation depends primarily on how the adsorbent, the adsorbate, and the interactions between them are described.

For crystalline materials, such as MOFs and COFs, for which the coordinates of all solid atoms are known from diffraction experiments, the adsorbent can be described in crystallographic detail. For amorphous materials, like porous carbons or low-crystallinity polymers, a generic surface model structure, such as graphite or graphene, and a pore model, such as a slit, cylinder, or sphere, are usually adopted. Nevertheless, various attempts have been made to more
Studying and selecting nanoporous materials for $\mathrm{H}_{2}$ storage applications is challenging due to the rapid growth in the number of new structures and the time-consuming nature 
accurately model complex amorphous pore networks [79]. Methods include the use of virtual porous carbon [80] and finite wall thickness models [81], quenched molecular dynamics [82], simulated polymerisation algorithms [83], and the packing of 3D carbon nanostructures [84].

Molecular $\mathrm{H}_{2}$ is typically modelled either as an uncharged sphere [85] or as a single mass centre, but threepoint-charged, dumbbell [86]. The latter accounts for the molecular quadrupole moment by considering two positive charges, $q$, at the ends of the dumbbell, and a negative charge, $-2 q$, at the centre of mass. In most cases, a 12-6 Lennard-Jones (LJ) potential-plus electrostatic interactions for charged $\mathrm{H}_{2}$ models-is used to represent the $\mathrm{H}_{2}-$ $\mathrm{H}_{2}$ interactions, with different sets of LJ parameters considered for either the spherical or dumbbell $\mathrm{H}_{2}$ models [87]. The Morse potential has also been used as it can be adjusted to fit a particular force field (FF). More complex models are also available [88, 89]. In addition, the quantum nature of $\mathrm{H}_{2}$ becomes evident at low temperatures, in small pores and at high densities [39, 87, 90, 91]. There are two main ways of accounting for quantum effects, although alternatives are being developed [91]. The first is to use the Feynman-Hibbs (FH) correction [92], which is an expanded version of the LJ potential [39]. In most cases, particularly above $50 \mathrm{~K}$, this is sufficiently accurate. The second is the path integral MC formalism outlined by Wang and Johnson [90], which is more accurate but is also more computationally demanding.

The $\mathrm{H}_{2}$-solid interactions are often described using generic classical FFs, such as the universal force field (UFF) [93], DREIDING [94], and the optimised potential for liquid simulations (OPLS) [95], but this approach is limited by the accuracy of a given FF to describe the interactions of $\mathrm{H}_{2}$ with all the framework atoms [78]. In some cases, classical approximations may fail, particularly when short-range interactions of $\mathrm{H}_{2}$ with metal centres, for example, are dominant [96]. When Coulombic interactions are important, FFs should also be supplemented with atomic partial charges. These can be calculated using Mulliken population analysis [97], charge partitioning methods [98] or with the aid of cluster-based electrostatic potential fitting (e.g. CHelpG [99] and RESP [100]). New electrostatic potential-based methods for periodic solids include REPEAT [101, 102] and DDEC [103, 104], while charge equilibration methods can be used for fast, highthroughput calculations, at the expense of accuracy [105]. Determination of atomic charges can be avoided by using full DFT-based electrostatic potential maps of the material [106], but this is computationally expensive.

The most accurate strategy for developing case-specific $\mathrm{H}_{2}$-solid interactions is to perform QC calculations, as discussed next. These methods can be very accurate and are thus recommended for the study of novel systems, in which the adsorption mechanism is unknown, and to probe very specific interactions. However, such multiscale approaches are computationally intensive. Detailed information can be found in recent reviews focussing on MOFs [107-109].

\subsubsection{Quantum chemical (QC) calculations}

There are two main types of QC calculation: wave function theory (WFT) and electronic density functional theory (DFT). They have many similarities since they share a number of mathematical approximations. In both cases, the Schrödinger equation is solved in order determine the properties of a molecular system using different approximations, including the Born-Oppenheimer approximation, the representation of the wave function as a Slater determinant and the basis set approximation.

The Hartree-Fock (HF) theory underpins both WFT and DFT, but it neglects the dynamical correlation of the electrons in the system, which is fundamental to the calculation of several properties, including the energy of the system. Inclusion of the effect of the dynamic motion of electrons is essential when dealing with molecular systems in which weak interactions are dominant, as is the case for $\mathrm{H}_{2}$ physisorption. In order to include dynamic electron motion, several WFT methods have been developed, including single-reference methods, such as Møller-Plesset (MP) perturbation or coupled cluster (CC) methods, and multireference methods; however, the latter are rarely used because they are computationally demanding. The most common is second-order MP perturbation theory (MP2) [110], in which electron correlation is treated as an additive perturbation to the one-electron operators. CC methods have also been used for $\mathrm{H}_{2}$ adsorption in nanoporous materials, but they are limited to systems with only a few atoms due to their computational cost. Nevertheless, CC methods serve as a benchmark in order to check the accuracy of other single-reference or DFT methods; $\operatorname{CCSD}(T)$ at the basis set limit, in particular, is considered the gold standard in computational chemistry, although care should be taken because results obtained using this method can still contain errors [109].

Accurate calculations depend not only on the selection of the theoretical method but also on the choice of basis set. The most accurate result for a given method can be achieved using an infinite expansion for each molecular orbital. A small loss of accuracy is expected in the calculated energy values when using finite basis sets, which can be retrieved if a complete basis set (CBS) scheme is applied. Another error originating from the incompleteness of basis sets is the basis set superposition error (BSSE), which artificially increases the calculated energy of the system. If a method that can treat this error is applied, such 
as the counterpoise (CP) method [111], a $20-50 \%$ reduction in the calculated interaction energy for $\mathrm{H}_{2}$ adsorption on carbon nanotubes or MOFs has been found.

DFT uses the idea that the spatial distribution of electron density uniquely determines the ground-state wave function, and vice versa, while if the universal density functional (i.e. the functional that uses the electron density to calculate the energy) is available, the ground-state energy can be obtained by variation. Following the work of Kohn and Sham [112], the approximate functionals of DFT partition the energy of the system into several terms, most of which are functions of the electron density, except the nuclear repulsion term. The different flavours of DFT arise from the choice of the exchange-correlation term of the energy, which accounts for the remaining (non-classical) terms and can be further separated into two functionals of the electron density: the exchange functional (same-spin electron interaction) and the correlation functional (mixedspin electron interaction). The different forms of these functionals are broadly known as approximations of DFT.

The earliest were based only on local electron densities [local density approximation (LDA)], while gradient approximations [generalised gradient approximation (GGA)] depend additionally on the density gradient [109]. They have widely been used to study $\mathrm{H}_{2}$ adsorption in carbon-based materials and MOFs, with the most common examples being PBE, PW91, BLYP, and BP86. Although these approximations include terms that treat electron correlation, they can fail to correctly describe the interaction of $\mathrm{H}_{2}$ with solids and to predict accurate interaction energies. Beyond LDA and GGA, hybrid functionals that include a percentage of non-local exchange obtained from HF calculations have been used to study adsorption, with B3LYP being the best known. Others include the B3PW91 and PBE0 functionals. Other categories include meta-GGA and hyper-GGA functionals, but these are rarely used in $\mathrm{H}_{2}$ storage studies. For a detailed description of exchange correlation functionals, see Odoh et al. [109].

A drawback of DFT is the rather poor description of weak interactions, which are important in adsorptive gas storage [78]. This is due to the failure of the functional to accurately describe medium- to long-range correlations. However, attempts have been made to develop DFT methods that are able to correctly account for dispersion interactions. These include the use of a non-local dispersion term in the correlation functional (vdw-DF), the use of a non-local term in the functional to account for mediumrange correlation, and the addition of a pairwise contribution to the electronic energy due to dispersion interactions (DFT-D). They have all been successfully applied to gas adsorption in MOFs and outperform the corresponding pure GGA or hybrid functionals without increasing computational effort.
DFT methods are faster than WFT and can treat larger systems. Moreover, DFT can be applied to a fragment of a material or to a periodic cell, whereas WFT can only be applied to a small fragment. However, WFT can be very accurate and the way to increase the accuracy is known. In contrast, DFT methods require an appropriate functional to be found. The main challenge in this field is the development of more efficient methods and algorithms that offer improved accuracy for a given computational cost. For the modelling of $\mathrm{H}_{2}$ adsorption, in particular, the accurate but efficient description of weak interactions is a clear priority.

\subsubsection{Discussion on computational modelling}

Despite recent progress, GCMC simulation methods could be further improved because there are problems that have not yet been resolved or fully investigated. There are also inherent shortcomings in GCMC methodology that should always be considered. For instance, a technical problem surfaces at high adsorbate densities. When pores are almost full, or the adsorbate molecules are highly confined (e.g. in ultramicropores), the normal GCMC technique fails due to the low acceptance ratio for insertion. This renders the exploration of phase space extremely slow. Several biasedGCMC techniques have thus been developed to overcome this problem [113]. This effect is particularly relevant to large molecules, such as aromatics, adsorbed in small cavities, but it may also play a significant role in $\mathrm{H}_{2}$ adsorption simulations when high densities (high pressures) and/or very narrow channels are considered [114].

Another issue is the ability of pairwise interactions to adequately describe the adsorbate-adsorbent system [78]. Many-body interactions can, in principle, be included by correctly parameterising the $\mathrm{LJ}$ parameters to fit the bulk phase behaviour of $\mathrm{H}_{2}$. It is then assumed that the behaviour of the pore confined phase is the same as the bulk, or that a particular set of LJ parameters can still describe the behaviour under confinement. However, the contributions of many-body interactions may be very different under confinement, so different case-specific LJ parameters should be used for each pore model. This is more than just a geometric consideration because in adsorption a foreign body is also included (the solid) and therefore the third body, in three-body interactions, for example, may be a framework ion. Further details on the importance of this can be found in Kostov et al. [115].

With regard to future challenges, the requirements differ depending on the material type. For example, a regular pore model is normally used to describe amorphous materials, which in reality consist of a very complex pore network. Pore connectivity is seldom considered, and simulations are based on individual pore models. These models may work well for relatively ordered mesoporous 
materials, but not for disordered microporous materials, especially those exhibiting ultramicroporosity, which are of most interest for $\mathrm{H}_{2}$ storage.

Another issue is that an energetically homogeneous surface is normally used to construct pore models. However, real carbon surfaces, for instance, have a degree of inhomogeneity induced by surface heteroatoms and functional groups, but also crystal defects, local curvature, geometrical imperfections, and a lack of long-range periodicity. Accounting for surface inhomogeneity and its effects on adsorption has been one of the most challenging and important topics in adsorption science for over 30 years [20]. Several mathematical approaches exist to determine the amount of inhomogeneity, but no satisfactory way of efficiently including this in molecular simulations has emerged. Energetic inhomogeneity is coupled with the inherent inhomogeneity created by the presence of pores of differing size, a common characteristic of non- or poorly crystalline materials. Specific inhomogeneities such as functional groups or lattice defects can be added to carbon surfaces, and their effect on $\mathrm{H}_{2}$ adsorption studied; currently, however, this can only be done using an explicit atomistic description of the surface [116]. Notable approaches towards the development of a mean-field description of the heterogeneity of adsorbent surfaces are QSDFT (quenched solid density functional theory) [117] and 2D-NLDFT (non-local density functional theory) incorporating energetic heterogeneity and geometric corrugation $[118,119]$. The future application of such meanfield approaches to the GCMC simulation of $\mathrm{H}_{2}$ adsorption by carbons can be expected to significantly improve upon the currently used methods of representing heterogeneity in these and related materials.

For crystalline adsorbents, the pore size and shape are known, so irregularity is less relevant; however, simulations are typically performed on idealised, fully desolvated systems, which can result in disagreement with experiment [108]. For example, the boundary conditions used in GCMC simulations assume crystals of infinite size but real materials consist of small crystals, with defects, intercrystalline voids, and fused crystallites, while in many MOFs, the complete removal of solvents is practically impossible. Moreover, the framework atoms are frequently assumed to be fixed, even though the structure is known not to be rigid; in fact, several pertinent phenomena, including structural framework transitions, and breathing or gating mechanisms in MOFs, for example, have been widely observed [120]. In such cases, optimisation of lattice constants and atomic positions, and consideration of the effects of framework flexibility on adsorption is required. The latter can be achieved using molecular dynamics (MD) [39], osmotic thermodynamic ensemble MC simulations or, more efficiently, hybrid MC/MD (hybrid Monte Carlo, or HMC)
[121-123], in which short MD trajectories are considered as MC moves, allowing better sampling of the host framework flexibility by following its collective motions. More details can be found in recent reviews [120, 124].

Consideration of the above problems and the study of their effect on adsorption remains a significant challenge. Furthermore, the development of a more accurate and less case-specific modelling approach would be a convenient tool for MOFs, due to the number of synthesised structures. The development of a "MOF force field" built on the basis of accurate quantum-level calculations and validated using available experimental data for families of MOFs sharing similar chemical characteristics would be an invaluable future asset.

The use of high-throughput computational screening is also a notable development. A series of databases containing a large number of porous materials have recently been reported [125-128]. This offers the potential for screening materials for $\mathrm{H}_{2}$ storage. The $\mathrm{H}_{2}$ storage capacity can also be correlated to the characteristics of different materials in order to focus on the most promising and to guide the synthesis and tailoring of new MOFs. Colón et al. [129], for example, considered frameworks functionalised with $\mathrm{Mg}$ and correlated the uptake to the degree of $\mathrm{Mg}$ functionalisation and the physical properties of the frameworks. Goldsmith et al. [130] also used high-throughput methods to determine promising materials for $\mathrm{H}_{2}$ storage. In contrast to other reports, however, the screening in this study included real rather than hypothetical frameworks, using data mining techniques on a vast catalogue of existing MOFs in the Cambridge Structural Database (CSD). Results for approximately 20,000 structures showed that the relationship between gravimetric and volumetric $\mathrm{H}_{2}$ storage density is concave downward (see Fig. 5). The use of these high-throughput methods in the future can be expected to contribute significantly to the search for new nanoporous materials for $\mathrm{H}_{2}$ storage.

\section{Materials}

Many different porous materials have been investigated for adsorptive $\mathrm{H}_{2}$ storage, including zeolites [133], various types of porous carbon [134-136], MOFs [16, 137-139], and porous organic polymers [140, 141]. However, as already noted, the interaction of $\mathrm{H}_{2}$ with most surfaces is weak and high $\mathrm{H}_{2}$ uptakes are limited mostly to low temperature conditions, around $77 \mathrm{~K}$, and to materials containing micropores, in which the adsorption potentials from the opposing pore walls overlap. As shown in Fig. 1, an approximately linear relationship between the gravimetric capacity and BET surface area has been observed [7, 142], although the saturation capacity of an adsorbent is ultimately limited by its pore volume [137]. 


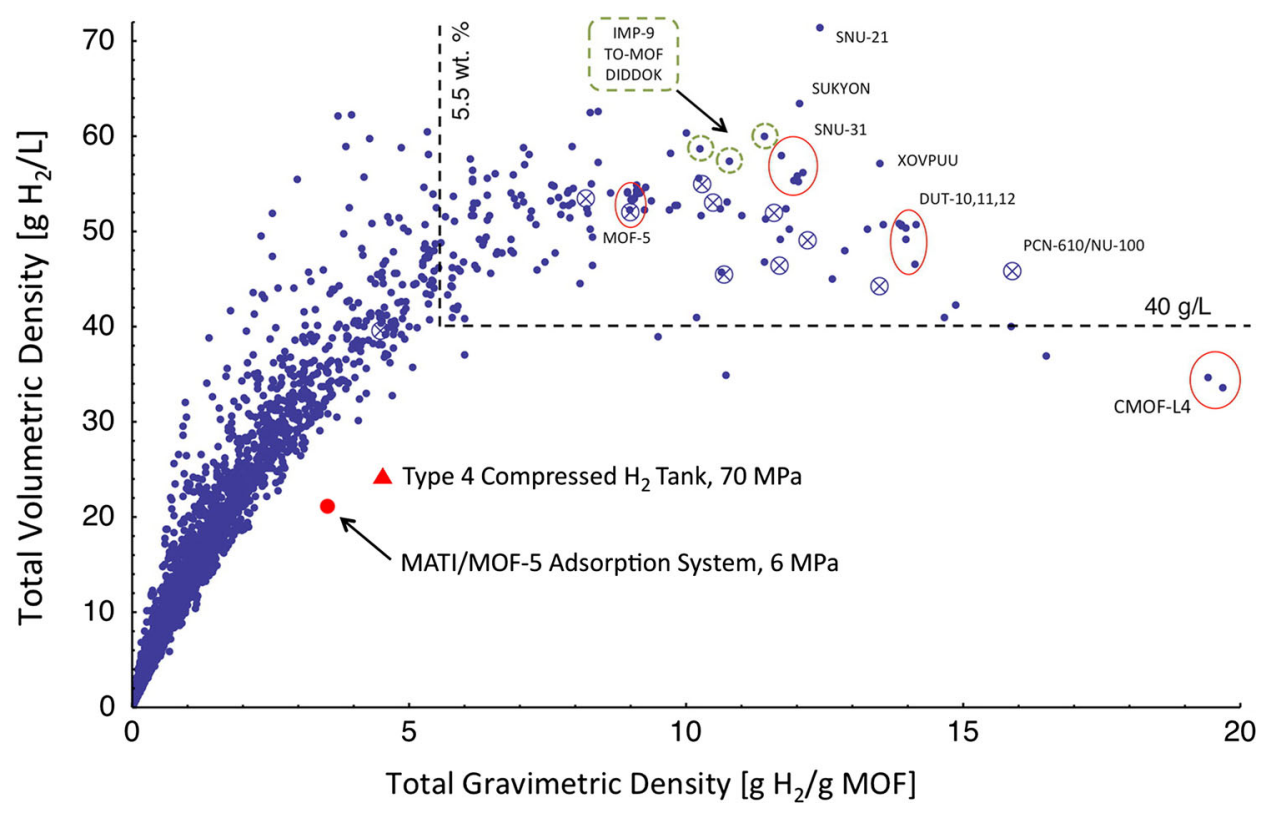

Fig. 5 A plot of total volumetric versus gravimetric density at $77 \mathrm{~K}$ for 20,000 MOFs in the Cambridge Structural Database (CSD) determined using high-throughput computational screening [130]. The dashed lines indicate the current 2020 US Department of Energy (DOE) volumetric and gravimetric hydrogen storage system targets. Note that the results plotted in blue are for materials only. The values for complete storage systems incorporating these adsorbents will be

The highest gravimetric capacities have thus been reported for materials with very high surface areas and large pore volumes. MOF-177, for example, has an excess $\mathrm{H}_{2}$ adsorption capacity of $\sim 7.5 \mathrm{wt} \%$ at $7.0 \mathrm{MPa}$ and $77 \mathrm{~K}$ [143], while an even higher value of $8.6 \mathrm{wt} \%$ has been reported for MOF-210, under essentially the same conditions [144]. MOF-177 and MOF-210 have reported BET surface areas of approximately 4700 and $6250 \mathrm{~m}^{2} \mathrm{~g}^{-1}$, respectively. Increasing surface area therefore offers a route to increasing gravimetric capacity, but this approach has limitations. Firstly, it leads primarily to an increase in gravimetric capacity only at low temperatures, and secondly, there is a physical limit to the achievement of even higher surface areas. Furthermore, materials with the highest reported surface areas also tend to have larger pores. This, in turn, leads to a reduction in the adsorption potential overlap responsible for the stronger $\mathrm{H}_{2}$-solid interactions in materials with very narrow pores. Larger pores are likely to lead to lower total volumetric capacities (see Sect. 2.2) because in larger pore materials, particularly those approaching the mesoporous regime $(>2 \mathrm{~nm}), \mathrm{H}_{2}$ is more likely to form a gas-like phase in the core of the pores.

It can be seen that achieving high storage capacities at near-ambient temperatures thus requires an approach other than simply increasing surface area. Furthermore, both the considerably lower due to the factors discussed in more detail in Sect. 5; for example, the figures for a recent prototype adsorption system, labelled "MATI/MOF-5" (see [131] for more detail), and for a type 4 compressed $\mathrm{H}_{2}$ storage system [132] are also shown (in red). (Reproduced and modified with permission from [130] (http://pubs. acs.org/doi/pdf/10.1021/cm401978e). The red symbols and labelling have been added to the original figure)

volumetric and gravimetric capacities of materials need to be considered. High gravimetric capacities result in lighter tanks, but a poor volumetric capacity increases bulk. These aspects are correlated, and it is important not to focus on one to the detriment of the other. To increase either the volumetric or gravimetric capacity of a material at nearambient temperatures, it is necessary to increase the enthalpy of adsorption by increasing the strength of the interaction between $\mathrm{H}_{2}$ and the material. This could potentially be achieved by altering the chemical nature of the adsorbent, but it is a challenge due to the properties of molecular hydrogen. Other options include the exploitation of framework flexibility, which can lead to hysteretic $\mathrm{H}_{2}$ adsorption behaviour, and modification of the $\mathrm{H}_{2}$ adsorption behaviour of materials using novel concepts, such as core-shell architectures [145]. Each of these challenges will be considered below.

\subsection{Volumetric versus gravimetric capacity}

The correlation between volumetric and gravimetric capacity was illustrated in the study by Goldsmith et al. [130]. As noted in the previous section, a concave relationship between the volumetric and gravimetric capacities of MOFs was found. The materials with the highest gravimetric capacities thus exhibit lower volumetric 
capacities than some materials with higher volumetric capacities. The results of this study are shown in Fig. 5. These two factors clearly need to be balanced.

One strategy to help overcome limitations in volumetric capacity is pelletisation, which can increase the volumetric uptake of a given material in a practical engineered form (see Sect. 5.1). Also, for MOFs, there is potential for framework interpenetration to increase the surface area of a given material per unit volume. The presence of additional skeletal material from the interpenetrated frameworks in a given volume might be expected to result in a concomitant decrease in the gravimetric capacity; however, studies have suggested that interpenetration can increase both the volumetric and gravimetric capacities of some materials [146].

It is also worth noting the importance of considering the usable or deliverable capacity of a material [61, 147-152], rather than just its total or absolute capacity (as discussed in Sect. 2.2). This can be defined as the amount of $\mathrm{H}_{2}$ stored reversibly between the maximum storage pressure and the delivery pressure of a practical storage unit. The latter is determined by the required back pressure, for example the pressure practically required by a fuel cell stack. For a given set of operating conditions, the usable capacity depends upon the $\mathrm{H}_{2}$ adsorption properties of the adsorbent. It also exhibits a peak when plotted against temperature, so that there is an optimum operating temperature for each material, which tends to be higher for materials with higher enthalpies of adsorption. The usable capacities of different nanoporous materials are discussed in more detail by Schlichtenmayer and Hirscher [153].

\subsection{Increasing the $\mathrm{H}_{2}$ interaction strength}

In 2006, Bhatia and Myers [147] considered the optimal enthalpy of adsorption for achieving ambient temperature $\mathrm{H}_{2}$ storage in nanoporous materials. Using a simple model, assuming Langmuir-type behaviour (see Sect. 3.1), they concluded that the optimum enthalpy of adsorption for the delivery of $\mathrm{H}_{2}$ from a hydrogen store between the pressures of 3.0 and $0.15 \mathrm{MPa}$ was $\approx 15 \mathrm{~kJ} \mathrm{~mol}^{-1} \mathrm{H}_{2}$. Other studies reached similar conclusions, although a higher value is sometimes quoted [15, 78]. For example, Bae and Snurr [148] suggested a value of approximately $20 \mathrm{~kJ} \mathrm{~mol}^{-1} \mathrm{H}_{2}$ based on GCMC simulations (see Sect. 3.2.1) of $\mathrm{H}_{2}$ adsorption by a series of MOFs over a wider pressure range, up to $12 \mathrm{MPa}$. To put this in context, $\mathrm{H}_{2}$ adsorption by carbons has an isosteric enthalpy of adsorption of approximately $6 \mathrm{~kJ} \mathrm{~mol}^{-1}$ [147].

Amongst the newer materials, MOFs have the potential to achieve a higher enthalpy of adsorption due to the presence of open metal sites and increased local charge densities in the pores of some materials. For example, the M-MOF-74 (M: $\mathrm{Mg}^{2+}, \mathrm{Co}^{2+}, \mathrm{Ni}^{2+}$, and $\mathrm{Zn}^{2+}$ ) series, which is also known as CPO-27, has a high density of open metal sites. The trend, in this case, for the $\mathrm{H}_{2}$-metal interaction strength was found by Pham et al. [154] to be Ni-MOF-74 > Co-MOF-74 > Mg-MOF-74 > Zn-MOF-

74; similar findings have also been reported by Rosnes et al. [155]. This behaviour is surprising because one would expect higher $\mathrm{H}_{2}$ binding in the case of Mg-MOF-74 since $\mathrm{Mg}^{2+}$ is small and is therefore the hardest cation (high partial charge) in the above series. The observed trend can be explained on the basis of the different polarisabilities of the metal cations. Theoretical calculations showed that the higher the contribution from polarisation, the stronger the $\mathrm{H}_{2}-$ metal interaction.

With regard to local charge densities, the study of MOFs with either positively or negatively charged frameworks would be an interesting topic for future work. In the rare case of a cationic rht-MOF with $\mathrm{NO}_{3}{ }^{-}$anions acting as counterions, it has been demonstrated that $\mathrm{H}_{2}$ adsorption occurs first near the $\mathrm{NO}_{3}{ }^{-}$ions because of their preferential interactions with $\mathrm{H}_{2}$ [156]. This finding is interesting considering that this rht-MOF also contains open metal sites (dimeric copper paddlewheel units) that usually show the strongest interaction with $\mathrm{H}_{2}$. Anionic MOFs are more abundant; they are usually obtained when metal cations with +3 oxidation states such as $\mathrm{In}^{3+}, \mathrm{Ga}^{3+}$, and lanthanides are combined with carboxylate-based organic linkers. In this case, the extra framework charge-balancing cations provide strong $\mathrm{H}_{2}$ adsorption sites. In addition, these counterions are, in principle, exchangeable, which provides a potential route to $\mathrm{H}_{2}$ adsorption sites with tunable energetics. An example is the family of anionic zeolite-like MOFs (ZMOFs), which can be constructed from a variety of organic linkers, including 4,5-imidazoledicarboxylic acid $\left(\mathrm{H}_{3} \mathrm{ImDC}\right)$ or 4,6-pyrimidinedicarboxylic acid [157]. In these materials, the enhanced binding of $\mathrm{H}_{2}$ (9 $\mathrm{kJ} \mathrm{mol}^{-1} \mathrm{H}_{2}$ at zero surface coverage) can be attributed to the electrostatic field created by the counterions present in the pore cavities. Notably, there is an observed increase of almost $50 \%$ in the isosteric enthalpy of adsorption compared to corresponding neutral MOFs.

Another approach is the modification or design of the organic linkers in MOFs in order to increase the strength of their interaction with $\mathrm{H}_{2}$. There are two main mechanisms: the introduction of additional adsorption sites on the functional groups and the secondary effect of the functionalities on the polarity of the framework [158]. The latter can increase the $\mathrm{H}_{2}$ affinity of the secondary building unit. An example is provided by a study of $\mathrm{H}_{2}$ adsorption in Zn-based MOFs containing internally polarised organic units [159]. The use of 2,6-azulenedicarboxylate in MOF650 , instead of the nonpolar 2,6-naphthalenedicarboxylate linker used in IRMOF-8, resulted in a high initial isosteric enthalpy of adsorption, of $6.8 \mathrm{~kJ} \mathrm{~mol}^{-1} \mathrm{H}_{2}$, compared to its 
nonpolar counterpart. Another example is the introduction of amide functional groups, which has been shown to increase the interaction strength of $\mathrm{H}_{2}$ [160]. Mixed linker strategies can also be used [161]. From a synthetic point of view, there are various ways of modifying MOFs, including linker exchange, chemical functionalisation, and postsynthetic cation exchange. Cohen [162] covered the postsynthetic chemical modification of MOFs in some detail, while Deria et al. [163] reviewed the use of linker, nonbridging ligand and metal ion exchange to modify these materials. MOF surfaces can also be modified in various ways [164]. Further investigation of the use of these approaches to improve the $\mathrm{H}_{2}$ storage properties of MOFs would seem both likely and worthwhile.

A relatively new class of materials that are yet to receive a significant amount of attention for $\mathrm{H}_{2}$ storage are nanoporous molecular crystals. These consist of discrete molecules interconnected via non-covalent interactions, rather than covalent or coordination bonds [165-168]. They are formed by removing guest molecules from an inclusion compound. This normally results in a non-porous solid, but permanently porous materials with high BET surface areas, up to $\sim 3750 \mathrm{~m}^{2} \mathrm{~g}^{-1}$, have been reported [169]. There are several types of nanoporous molecular crystal, including those with intrinsic and extrinsic porosity [170], but intrinsically porous organic cage compounds [166] seem particularly interesting for $\mathrm{H}_{2}$ storage applications. It is possible, for example, that such materials can be functionalised with multiple open metal sites inside one cage and that these opposing strong sites may increase the $\mathrm{H}_{2}$ interaction strength further.

\subsection{Flexible frameworks and core-shell materials}

Hysteretic $\mathrm{H}_{2}$ adsorption has been reported for a number of MOFs [171-175], although it is relatively rare. For $\mathrm{H}_{2}$ storage, the interest in this behaviour lies in the potential for nanoporous materials to release $\mathrm{H}_{2}$ at a different pressure to that used for $\mathrm{H}_{2}$ charging or to induce $\mathrm{H}_{2}$ release via temperature changes, from materials in which the $\mathrm{H}_{2}$ would otherwise remain trapped, either thermodynamically or kinetically. This is in contrast to the behaviour exhibited by most-more rigid-materials that show completely reversible $\mathrm{H}_{2}$ adsorption that can be accurately described by the isotherm models covered in Sect. 3.1. In addition, if flexibility is present, the expansion and contraction of the framework can be accompanied by a change in heat that may act positively on the thermodynamics of gas uptake and release. This was demonstrated recently for two flexible MOFs, Co(bdp) and $\mathrm{Fe}(\mathrm{bdp})$, that exhibit hysteretic methane adsorption [176]. Further development of MOFs showing hysteretic $\mathrm{H}_{2}$ adsorption behaviour could potentially allow the tuning of materials with properties specifically suited to the requirements of $\mathrm{H}_{2}$ storage; however, only preliminary measurements currently exist. Further experiments on well-defined model systems will be necessary to better understand this phenomenon.

Core-shell materials, meanwhile, consist of a core of one material encapsulated in a shell of another [145, 161, $164,177,178]$. This offers the possibility of combining the behaviour of the core and the shell, to provide functionality arising from the different properties of the two components. For example, the shell could act as a gate for uptake and release of the gas stored in the core; the idea being that the gate opening of the shell would occur at a well-defined temperature, thus releasing the $\mathrm{H}_{2}$ stored in the core. This may result in an isotherm of a form closer to that of a classical hydride than the reversible type I behaviour exhibited by most nanoporous materials. $\mathrm{H}_{2}$ adsorption and desorption measurements have not yet been performed on such core-shell materials, so this would be an interesting avenue for future research. Furthermore, although a number of core-shell MOFs have been reported [145, 161, 164, 177], other nanoporous materials have also been used [178]. It would thus seem possible to form core-shell architectures from many different combinations of materials, which could in turn lead to composites with properties of interest for $\mathrm{H}_{2}$ storage.

It should be emphasised that, at the time of writing, both flexible frameworks and core-shell materials are a long way from any application, since very few measurements using $\mathrm{H}_{2}$ are known. Measurements on model systems must be established in order to better understand the microscopic mechanisms, prior to tailoring materials with properties designed specifically for $\mathrm{H}_{2}$ storage.

\section{Storage systems}

The engineering objectives and operating requirements for storage systems are defined by the intended application. This discussion considers automotive use, which has been the focus of much recent attention [179]. Technical targets were established by the U.S. Department of Energy (DOE) together with the automotive industry [180]. The most challenging of these for adsorption-based systems are gravimetric capacity, volumetric capacity, and charging time. The first is limited by adsorbent characteristics. Volumetric capacity is also material specific, but approaches are available to reduce the adsorbent volume, and hence that of the system. Thirdly, since adsorption occurs very rapidly, charging time is not limited by the adsorption kinetics but by heat and mass transfer.

Gas adsorption is exothermic so heat is typically released during charging. The total amount released depends upon the enthalpy of $\mathrm{H}_{2}$ adsorption. For MOF-5, for example, this is 
3.5-4.5 $\mathrm{kJ} \mathrm{mol}^{-1} \mathrm{H}_{2}$, depending on the loading [181]. In a system storing $5.6 \mathrm{~kg}$ of usable $\mathrm{H}_{2}, 10 \mathrm{MJ}$ of heat must therefore be dissipated due to adsorption alone. In addition, the system is refuelled from a heated (empty) state and then cooled to a charged ( $f u l l$ ) state. For economic reasons, liquid nitrogen $\left(\mathrm{LN}_{2}\right)$ can be used for cooling, so the tank will be at around $77 \mathrm{~K}$ when full. $\mathrm{H}_{2}$ adsorption isotherms show that over $95 \%$ of the $\mathrm{H}_{2}$ is released by $160 \mathrm{~K}$. Accounting for the mass of the adsorbent and an Al type 1 vessel, with a working pressure of $6.0 \mathrm{MPa}$, the stored thermal energy would be another 17.5 MJ. This must also be dissipated to reach the full state. Operating pressure is critical to performance and cost. Vessels operating below 6.0 MPa can be all-metal (type 1) tanks, which are relatively inexpensive. Above this, however, tank weight increases significantly with increasing pressure. Lighter composite wrapped over metal liner (type 3 ) or composite wrapped over polymer liner (type 4) tanks can be used but at significantly increased cost.

Dissipation of $27.5 \mathrm{MJ}$ of heat is a serious challenge, particularly when tanks must be charged rapidly. For a refuelling time of $3.3 \mathrm{~min}$, for example, the required heat dissipation rate is $90 \mathrm{~kW}$. This problem is compounded by the low thermal conductivities of adsorbents. Charge cycle requirements dominate heat exchanger design because charging is performed in minutes while discharging occurs over hours. Hence, this will be the focus of the discussion in this section.

\subsection{Material configuration}

Adsorbents are usually synthesised in a finely granulated or powder form. Powder is ideal for increasing gas accessibility, but the interparticle void space is inefficient for gas storage, with its capacity limited to compressed gas densities. Some adsorbents pack densely to approximately $60 \%$ of their crystal density, the highest achievable value for randomly packed spheres. Other adsorbents are less dense due to their electrostatic nature and pack to only $20 \%$ of their crystal density [182]. This void space, while not volumetrically efficient, acts as a buffer tank that can supply $\mathrm{H}_{2}$ through a pressure drop without thermal intervention. Fine powder requires closely spaced heat flow augmentation, as in typical tube-fin heat exchangers, in which $\mathrm{Al}$ fins are arrayed in the powder adsorbent and kept in contact with a cooling/heating source that dictates the adsorbent temperature.

Alternatively, adsorbents can be densified by mechanical consolidation. MOF-5, for example, can bind to itself under relatively low compaction pressures [182]. However, caution is required when using mechanical methods because pore collapse can occur, leading to surface area loss at high compaction pressures. This is a particular problem for MOFs because the ligand structures can collapse irreversibly [183, 184]. Binders can be used in some cases, but this decreases gravimetric capacity.

\subsection{Thermophysical properties}

Models indicate that the thermal conductivity of an adsorbent bed for automotive storage systems with a refuelling time of $3.3 \mathrm{~min}$ must be in the range 1-3 $\mathrm{W} \mathrm{m}^{-1} \mathrm{~K}^{-1}$ in order to enable removal of the heat of adsorption. Ahluwalia et al. [185] suggested a minimum thermal conductivity target of $1 \mathrm{~W} \mathrm{~m}^{-1} \mathrm{~K}^{-1}$, which could be achieved by adding up to $20 \mathrm{wt} \%$ expanded natural graphite (ENG) in order to minimise the combined weight of the heat exchanger and the thermal conductivity enhancing media. However, Chakraborty and Kumar [186] designed a system that could use an adsorbent with a thermal conductivity of only $0.3-0.5 \mathrm{~W} \mathrm{~m}^{-1} \mathrm{~K}^{-1}$ by integrating a heating coil into the bed and relying on flowthrough cooling, as discussed below.

One of the first reports on the low thermal conductivity of MOFs was by Huang et al. [187]. For single-crystal MOF-5, it was found to be $0.32 \mathrm{~W} \mathrm{~m}^{-1} \mathrm{~K}^{-1}$ at ambient temperature, and $0.22 \mathrm{~W} \mathrm{~m}^{-1} \mathrm{~K}^{-1}$ near $100 \mathrm{~K}$. MOF-5 powder was shown by Ming et al. [182] to exhibit a lower thermal conductivity, depending on the density of the compacted powder. At $300 \mathrm{~K}$, values from $0.091 \mathrm{~W} \mathrm{~m}^{-1} \mathrm{~K}^{-1}$ at $0.35 \mathrm{~g} \mathrm{~cm}^{-3}$ to $0.16 \mathrm{~W} \mathrm{~m}^{-1} \mathrm{~K}^{-1}$ at $0.69 \mathrm{~g} \mathrm{~cm}^{-3}$ were found. Schlemminger et al. [188] stressed the importance of knowing the temperature-dependent thermophysical material properties. The effective thermal conductivity of $\mathrm{Fe}-\mathrm{BTC}$ in $\mathrm{H}_{2}$ was shown to decrease from $0.3 \mathrm{~W} \mathrm{~m}^{-1} \mathrm{~K}^{-1}$ at $300 \mathrm{~K}$ to $0.17 \mathrm{~W} \mathrm{~m}^{-1} \mathrm{~K}^{-1}$ at $80 \mathrm{~K}$. The heat capacity of the adsorbent also decreased from $950 \mathrm{~J} \mathrm{~kg}^{-1} \mathrm{~K}^{-1}$ at $300 \mathrm{~K}$ to $250 \mathrm{~J} \mathrm{~kg}^{-1} \mathrm{~K}^{-1}$ at $100 \mathrm{~K}$, indicating that an equivalent amount of energy at $100 \mathrm{~K}$ will cause a larger increase in temperature than at $300 \mathrm{~K}$. This is clearly an important consideration in system design.

As an alternative, Han et al. [189] suggested increasing the intrinsic thermal conductivity of MOFs by reducing the mass of the nodes and shortening the linkers, but this met with modest experimental success. Ren et al. [190] suggested increasing the thermal conductivity through the deposition of MOF material in porous Ni foam. This also facilitated the handling of the adsorbent. Thermal conductivity values exceeding $0.3 \mathrm{~W} \mathrm{~m}^{-1} \mathrm{~K}^{-1}$ have been achieved through compaction with ENG [191]. At a compact density of $0.35 \mathrm{~g} \mathrm{~cm}^{-3}$, neat MOF-5 powder had a thermal conductivity of $0.07 \mathrm{~W} \mathrm{~m}^{-1} \mathrm{~K}^{-1}$. This increased to $0.08,0.15$, and $0.39 \mathrm{~W} \mathrm{~m}^{-1} \mathrm{~K}^{-1}$ after the addition of 1 , 5, and $10 \mathrm{wt} \%$ ENG, respectively.

Directionality of the thermal conductivity due to compaction was reported by Fedchenia et al. [192]. They performed Hot Disk thermal conductivity measurements in 
three orthogonal directions on compacted MOF-5, incorporating $10 \mathrm{wt} \% \mathrm{ENG}$, with a density of $0.604 \mathrm{~g} \mathrm{~cm}^{-3}$. A thermal conductivity of $0.286 \mathrm{~W} \mathrm{~m}^{-1} \mathrm{~K}^{-1}$ was found in the pressing direction, with higher values of 1.49-3.45 $\mathrm{W} \mathrm{m}^{-1} \mathrm{~K}^{-1}$ in the perpendicular direction. The results were similar to those reported for a $\mathrm{MgH}_{2} / \mathrm{ENG}$ composite [193]. The heat transfer rate between the pelletised MOF-5 + $10 \mathrm{wt} \%$ ENG and the Hot Disk sensor was in the range $644-782 \mathrm{~W} \mathrm{~m}^{-2} \mathrm{~K}^{-1}$. This is an important consideration when integrating adsorbent pellets with a heat exchanger surface. Directionality of the thermal conductivity was also reported by Ming et al. [184]. A MOF-5 composite with $5 \mathrm{wt} \% \mathrm{ENG}$ at a density of $0.35 \mathrm{~g} \mathrm{~cm}^{-3}$ was shown to have a thermal conductivity of $0.15 \mathrm{~W} \mathrm{~m}^{-1} \mathrm{~K}^{-1}$ in the pressing direction and $0.6 \mathrm{~W} \mathrm{~m}^{-1} \mathrm{~K}^{-1}$ in the perpendicular direction, due to preferential alignment of the ENG flakes.

\subsection{Heat exchanger concepts}

Figure 6 shows several heat exchanger concepts. In each case, the adsorbent is packed around the heat exchange material allowing $\mathrm{H}_{2}$ to flow freely into the bed. The conventional tube-fin concept, shown in Fig. 6a, uses a series of tubes connected with $\mathrm{Al}$ fins to provide high thermal conductivity paths throughout the bed, which is packed between the plates and tubes. The spacing of the plates and tubes is critical, in order to minimise the mass, volume, and cost of the heat exchange system, while still providing adequate response to transient operating conditions. Optimisation can be performed using materials performance models, combined with finite element models to track mass and thermal flows within competing designs, as outlined by Hardy et al. [62] and Corgnale et al. [64].

A variation of the tube-fin design uses an $\mathrm{Al}$ honeycomb for fins, as shown in Fig. 6b. The adsorbent is packed in the honeycomb, together with heating/cooling channels. Lightweight $\mathrm{Al}$ foil is used for construction, with the hexagonal cells having dimensions approximately 3-9 mm, flat to flat. The honeycomb heat exchanger has a simple design, low cost, and a low volume. Another benefit is the ability to flow gas through long channels of adsorbent, which is advantageous for cooling purposes. For $300 \mathrm{~L}$ of adsorbent, this heat exchanger only costs around US\$100 and has a low volume of approximately 3.3 L.

Foams, as shown in Fig. 6c, d, in conjunction with heating/cooling tubes, are also being considered. Metal foams have been used successfully in metal hydride-based hydrogen reservoirs [194], but they are unsuitable for automotive applications due to their high cost $(\sim$ US\$280 $\mathrm{L}^{-1}$ ). Carbon foams are cheaper, with a comparable thermal conductivity, a lower density, and a low coefficient of thermal expansion. However, foams, in general, are difficult to impregnate with adsorbent, which is a major drawback.

Additives such as ENG can be used, either in a homogeneous distribution or inhomogeneously, as in layering, in order to increase its thermal conductivity. An example of a layered structure is shown in Fig. 6e. Such an approach has improved the thermal conductivity of MOF-5 by a factor of five at room temperature, with $10 \%$ ENG layered perpendicularly to the pressing direction [184]. Layering can limit design options, since the layers must be aligned perpendicularly to the pressing direction, but this method of incorporating high thermal conductivity paths in highly insulating adsorbent powders may be advantageous.

Another heat exchanger concept uses microchannels etched into metal plates. This technology was originally pursued by Wegeng et al. [195]. The microchannel design uses a series of fins containing microscale channels ( $\approx 200 \mu \mathrm{m}$ ) etched into them, as shown in Fig. 6f. The heat transfer fluid flows down one header tube, through the channelled fins, and up the return header, resulting in convective thermal energy transfer that keeps the surface temperature of the fins constant. The microchannel design is not limited by metal heat conduction, unlike conventional fins. The main benefits of the microchannel heat exchanger are its ability to work with compacted adsorbents and its relatively low mass and volume.

\subsection{Flow-through cooling}

In a flow-through system, $\mathrm{LN}_{2}$-chilled $\mathrm{H}_{2}$ is used to cool the adsorbent bed while the $\mathrm{H}_{2}$ is simultaneously being adsorbed [64]. This requires three to four times the volume of $\mathrm{H}_{2}$ that is adsorbed, with the remainder returned to the fuelling station for re-cooling. This simplifies the on-board adsorption system since only heating lines need to be added to the system; however, there is a trade-off with greater complexity at the fuelling station because the chilled $\mathrm{H}_{2}$ and its return must be accommodated.

A subscale prototype was demonstrated recently in a fully instrumented $0.5-\mathrm{L}$ vessel containing a honeycomb heat exchanger, the details of which will be published separately. Thermocouples were arranged both on the Al cell walls and in the adsorbent bed. The system included ten stacked honeycomb units with a resistance heating rod inserted down the centre for discharge. To cool during charging, chilled gas was passed through the honeycomb channels and out the end of the vessel. The system can be cooled rapidly from ambient temperature, using a cold gas flow of $80 \mathrm{~K} \mathrm{H}_{2}$ at a rate of $95 \mathrm{~L} \mathrm{~min}^{-1}$, chilled to $80 \mathrm{~K}$ at 6.0 MPa. The thermocouples mounted close to the central axis recorded initial warming due to adsorption, followed by rapid cooling. The embedded resistance heater can then be used to heat the bed during the discharge phase. 


\section{(a) Conventional Tube-Fin}

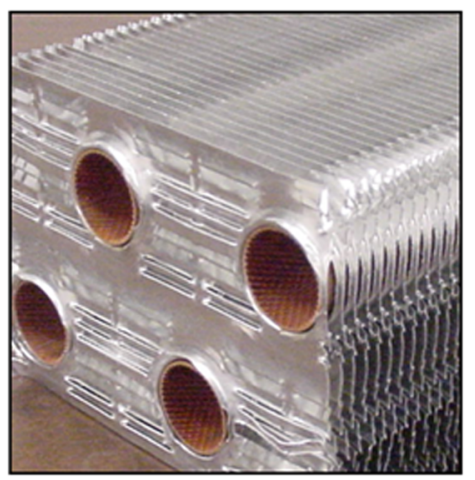

(c) Carbon Foam

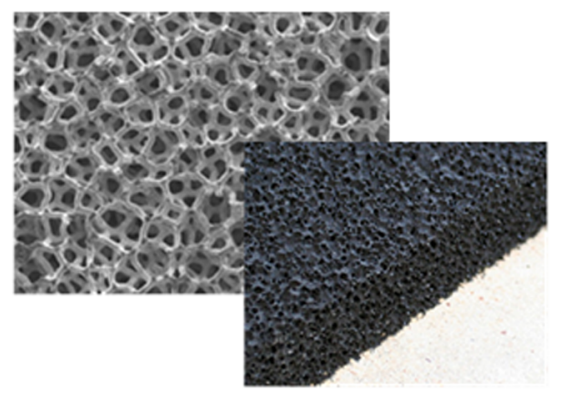

\section{(b) Aluminum Honeycomb}

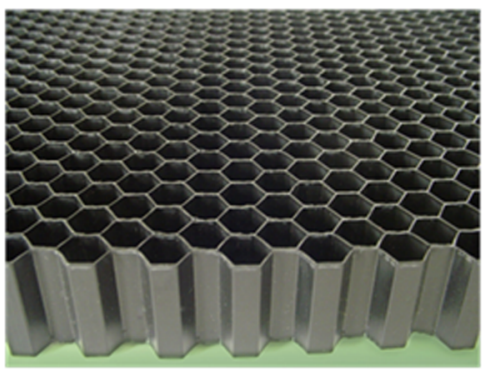

(d) Aluminum Foam

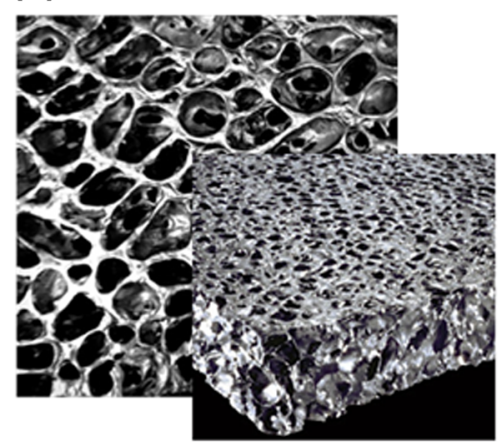

(e) Compacted and Augmented MOF Courtesy M. Veenstra, Ford Motor Co.

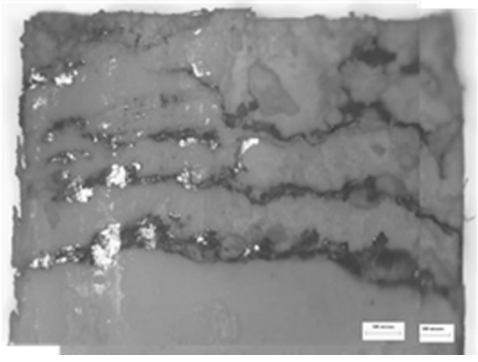

(f) Micro-Channel

Heat Exchanger

Courtesy K. Drost, Oregon State University
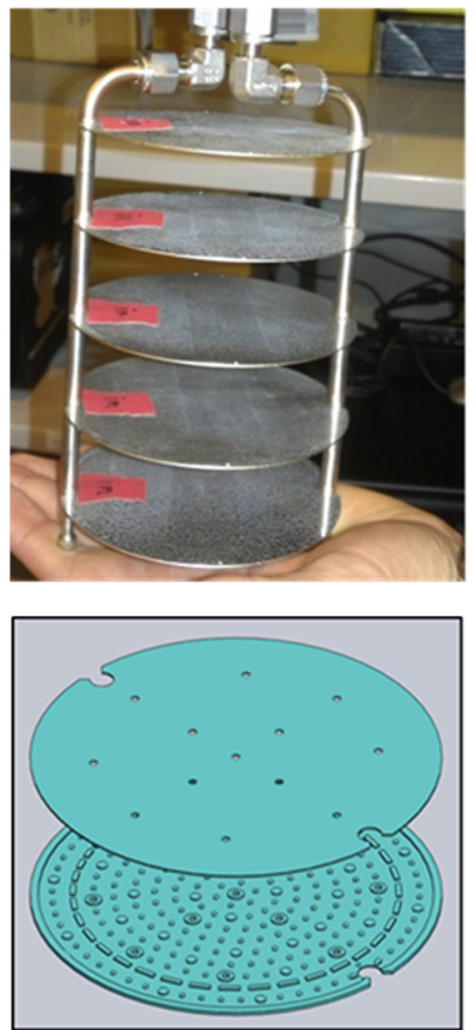

Fig. 6 Various heat exchanger concepts: a conventional tube-fin, b Al honeycomb, c carbon foam, d Al foam, e compacted MOF with layered ENG, and $\mathbf{f}$ microchannel heat exchanger

\subsection{Discussion on storage systems}

Using MOF-5, the majority of the US DOE technical targets can be achieved using advanced engineering methods and techniques $[131,196] . \mathrm{H}_{2}$ can be charged and discharged rapidly, and storage systems are robust enough to operate under all reasonable terrestrial conditions with minimal impact on performance. The remaining targets needing effort include (1) gravimetric density, (2) volumetric density, (3) fuel cost, and (4) loss of useable $\mathrm{H}_{2}$.

Gravimetric density targets can only be achieved using new materials with higher gravimetric capacities or materials that do not require cooling, for example those having an adsorption enthalpy of $20-30 \mathrm{~kJ} \mathrm{~mol}^{-1} \mathrm{H}_{2}$. However, this in turn could lead to fuelling station issues associated with dissipation of this heat during charging. In contrast, volumetric capacity can be partially addressed using more effective adsorbent consolidation methods. However, even at spherical powder packing densities, $40 \%$ of the volume is free space and able to only accommodate $\mathrm{H}_{2}$ at its gaseous density. Higher volumetric density adsorbents must therefore be developed. In automobile design, volume is more important than weight for several reasons, including the required changes to the vehicle frame design and its effects on range.

Fuel cost is directly associated with the use of $\mathrm{LN}_{2} . \mathrm{H}_{2}$ cost could be reduced by using lower $\mathrm{H}_{2}$ pressures of $6 \mathrm{MPa}$, rather than $70 \mathrm{MPa}$, which is becoming the standard for fuel cell vehicles. However, the addition of $\mathrm{LN}_{2}$ infrastructure at the fuelling station is likely prohibitive. 
The need for cryogenic temperatures also affects $\mathrm{H}_{2}$ loss. Even using multilayer vacuum insulation with a heat leak of less than $5 \mathrm{~W}$, venting of a fail-safe full tank begins after 3 days. Calculations indicate significant $\mathrm{H}_{2}$ will remain even under the harshest terrestrial conditions after 9 months; however, in many instances, the loss of $\mathrm{H}_{2}$ in a static situation may be unacceptable. The only viable solution to the problem of high fuel cost and the loss of useable $\mathrm{H}_{2}$ is the identification of adsorbents with higher enthalpies of adsorption.

\section{Discussion and conclusion}

This article has covered a number of the important aspects of research into hydrogen storage in nanoporous materials. The discovery and development of new materials undoubtedly plays a central role, with hydrogen storage being only one of many applications currently driving advances in materials chemistry [197]. However, the different experimental and computational approaches to their study for $\mathrm{H}_{2}$ storage also require attention. Firstly, the measurement of hydrogen uptake by materials, as discussed in Sect. 2.1, can be subject to errors that have led to concerns regarding the accuracy and reproducibility of hydrogen uptake data. No formal guidelines are currently available to help ensure accurate hydrogen sorption measurements are taken by following accepted protocols. This can lead to inconsistencies in the data reported in the literature. Furthermore, once data are measured and the excess adsorption calculated, there are ambiguities in the definition of the absolute or total capacity of a material that can be extracted using different assumptions, as discussed in Sect. 2.2; although efforts are underway to develop a more consistent approach. The use of net adsorption, for example, could provide an interesting alternative. Nevertheless, absolute adsorption isotherms measured at different temperatures can be analytically represented by the models mentioned in Sect. 3.1. Studies in this area, reporting detailed isotherm fitting of $\mathrm{H}_{2}$ adsorption isotherms measured at different temperatures, are relatively scarce compared to those reporting the $\mathrm{H}_{2}$ storage capacities of a material or groups of materials at one or two temperatures, 77 and $298 \mathrm{~K}$, for example. However, further studies validating the models for different adsorbents, particularly those exhibiting novel adsorption behaviour, would be valuable.

On a microscopic level, information can be obtained experimentally using, for example, neutron scattering techniques, as discussed in Sect. 2.3. There is clear scope for expanding the range of experimental conditions probed using neutrons - to higher temperatures, in particular-but also the wider use of $\mathrm{H}_{2}$ instead of $\mathrm{D}_{2}$ in diffraction studies.
The global development of higher-intensity neutron sources, with the concomitant improvement in neutron scattering instrumentation that can be expected, will certainly aid this task. Computational techniques are another option. Improvements in GCMC methodology to allow a better representation of amorphous or disordered and defective materials, for example, would be particularly valuable, as would the development of a transferable "MOF force field" that could accurately describe the $\mathrm{H}_{2}$-solid interactions for different groups of MOFs. With regard to quantum chemical calculations, the development of new, efficient methods that can accurately describe dispersion interactions, but with linear scaling with system size, for example, in terms of computational expense, would be particularly welcome. High-throughput computational screening of materials for $\mathrm{H}_{2}$ storage is another area in which important developments can be expected in the near future.

With regard to materials, there is a need to carefully consider both their volumetric and gravimetric capacities, while the usable capacity is practically important and must not be overlooked. Methods of increasing the interaction strength of $\mathrm{H}_{2}$ are also a key consideration for increasing the operational temperatures of nanoporous materials for $\mathrm{H}_{2}$ storage. Possible approaches include the use of open metal sites in MOFs and functionalisation of their organic linkers using, for example, post-synthetic modification. Nanoporous molecular crystals, including intrinsically porous organic cage compounds, are an example of a potentially interesting new material type that should be investigated further for $\mathrm{H}_{2}$ storage applications. Furthermore, MOFs exhibiting hysteretic $\mathrm{H}_{2}$ adsorption behaviour and core-shell materials are also interesting targets for future research because they have the potential to significantly increase the usable capacity.

Beyond the discovery of new materials, the further investigation and development of $\mathrm{H}_{2}$ storage tanks is also important. In Sect. 5, a number of relevant aspects were discussed, including methods of incorporating powders into large adsorbent beds, the thermal conductivity of materials, different heat exchange concepts, and the use of flow-through cooling. Both the gravimetric and volumetric capacities of practical tanks need to be increased. The volumetric capacity, which is a critical consideration for mobile applications, can be increased to a certain extent using alternative adsorbent consolidation methods and more efficient heat exchangers, but, ultimately, new highcapacity adsorbents with higher adsorption enthalpies are required. The use of such materials would also help ameliorate another problem with current storage units, which is the loss of useable $\mathrm{H}_{2}$ due to the required use of cryogenic temperatures. Nevertheless, any further improvements in storage tank design that can be introduced would be 
valuable in order to maximise the performance of the current state-of-the-art materials in real scenarios. All of the topics covered in this article would clearly be valuable targets for future research in the field.

Acknowledgments Open access funding provided by Max-PlanckInstitut für Intelligente Systeme. The authors acknowledge the contribution of the International Energy Agency (IEA) Hydrogen Implementing Agreement (HIA) from which this paper results, specifically the activities of Task 32: Hydrogen-based energy storage. Part of this research has been co-financed by the European Union (European Social Fund-ESF) and Greek national funds through the Operational Program "Education and Lifelong Learning" of the National Strategic Reference Framework (NSRF)—Research Funding Program: THALES. Part of the paper is also based upon work supported by the U. S. Department of Energy (National Nuclear Security Administration) under Award Number DE-FC36-09GO19006. Neither the United States Government nor any agency thereof, nor any of their employees, makes any warranty, express or implied, or assumes any legal liability or responsibility for the accuracy, completeness, or usefulness of any information, apparatus, product, or process disclosed, or represents that its use would not infringe privately owned rights. Reference herein to any specific commercial product, process, or service by trade name, trademark, manufacturer, or otherwise does not necessarily constitute or imply its endorsement, recommendation, or favouring by the United States Government or any agency thereof. The views and opinions of authors expressed herein do not necessarily state or reflect those of the United States Government or any agency thereof.

Open Access This article is distributed under the terms of the Creative Commons Attribution 4.0 International License (http://crea tivecommons.org/licenses/by/4.0/), which permits unrestricted use, distribution, and reproduction in any medium, provided you give appropriate credit to the original author(s) and the source, provide a link to the Creative Commons license, and indicate if changes were made.

\section{References}

1. M. Hirscher (ed.), Handbook of Hydrogen Storage: New Materials for Future Energy Storage (Wiley, Weinheim, 2010)

2. D.P. Broom, Hydrogen Storage Materials: The Characterisation of Their Storage Properties (Springer, London, 2011)

3. B. Panella, M. Hirscher, Adv. Mater. 17(5), 538 (2005)

4. B. Panella, M. Hirscher, H. Pütter, U. Müller, Adv. Funct. Mater. 16(4), 520 (2006)

5. R.C. Lochan, M. Head-Gordon, Phys. Chem. Chem. Phys. 8, 1357 (2006)

6. E. Klontzas, E. Tylianakis, G.E. Froudakis, J. Phys. Chem. Lett. 2(14), 1824 (2011)

7. M. Hirscher, Angew. Chem. Int. Ed. 50(3), 581 (2011)

8. D.P. Broom, K.M. Thomas, MRS Bull. 38(5), 412 (2013)

9. C.J. Webb, E.M. Gray, Int. J. Hydrog. Energy 39(1), 366 (2014)

10. T.P. Blach, E.M. Gray, J. Alloys Compd. 446-447, 692 (2007)

11. C.J. Webb, E.M. Gray, Int. J. Hydrog. Energy 39(13), 7158 (2014)

12. E.M. Gray, in Solid-State Hydrogen Storage, ed. by G. Walker (Woodhead Publishing, Cambridge, 2008), p. 174

13. C. Zlotea, P. Moretto, T. Steriotis, Int. J. Hydrog. Energy 34(7), $3044(2009)$
14. K.E. Hurst, P.A. Parilla, K.J. O’Neill, T. Gennett, Appl. Phys. A 122, 42(2016).doi:10.1007/s00339-015-9537-x

15. L.J. Murray, M. Dinca, J.R. Long, Chem. Soc. Rev. 38, 1294 (2009)

16. M.P. Suh, H.J. Park, T.K. Prasad, D.-W. Lim, Chem. Rev. 112(2), 782 (2012)

17. S. Gumma, O. Talu, Langmuir 26(22), 17013 (2010)

18. A.L. Myers, P.A. Monson, Adsorption 20(4), 591 (2014)

19. K. Murata, M. El-Merraoui, K. Kaneko, J. Chem. Phys. 114(9), 4196 (2001)

20. W. Rudzinski, D.H. Everett, Adsorption of Gases on Heterogeneous Surfaces (Academic Press, London, 1992)

21. A.V. Neimark, P.I. Ravikovitch, Langmuir 13(19), 5148 (1997)

22. B. Schmitz, M. Hirscher, in Hydrogen and Fuel Cells: Fundamentals, Technologies and Applications, ed. by D. Stolten (Wiley, Weinheim, 2010), p. 431

23. K.J. Gross, K.R. Carrington, S. Barcelo, A. Karkamkar, J. Purewal, S. Ma, H.-C. Zhou, P. Dantzer, K. Ott, T. Burrell, T. Semeslberger, Y. Pivak, B. Dam, D. Chandra, P. Parilla, Recommended Best Practices for the Characterization of Storage Properties of Hydrogen Storage Materials, US Department of Energy Hydrogen Program, 2012. http://www1.eere.energy.gov/hydrogenandfuelcells/ pdfs/best_practices_hydrogen_storage.pdf. Accessed 29 Nov 2015

24. P.A. Parilla, K. Gross, K.E. Hurst, T. Gennett, Appl. Phys. A. (2016 in press)

25. F.O. Mertens, Surf. Sci. 603(10-12), 1979 (2009)

26. B.T.M. Willis, C.J. Carlile, Experimental Neutron Scattering (Oxford University Press, Oxford, 2009)

27. M.P. Fang, P.E. Sokol, Y. Wang, Phys. Rev. B 50, 12291 (1994)

28. F.J. Bermejo, K. Kinugawa, C. Cabrillo, S.M. Bennington, B. Fåk, M.T. Fernández-Diaz, P. Verkerk, J. Dawidowski, R. Fernández-Perea, Phys. Rev. Lett. 84, 5359 (2000)

29. C.M. Brown, T. Yildirim, D.A. Neumann, M.J. Heben, T. Gennett, A.C. Dillon, J.L. Alleman, J.E. Fisher, Chem. Phys. Lett. 329(3-4), 311 (2000)

30. H.G. Schimmel, G.J. Kearley, M.G. Nijkamp, C.T. Visser, K.P. de Jong, F.M. Mulder, Chem. Eur. J. 9(19), 4764 (2003)

31. P.A. Georgiev, D.K. Ross, P. Albers, A.J. Ramirez-Cuesta, Carbon 44(13), 2724 (2006)

32. N.L. Rosi, J. Eckert, M. Eddaoudi, D.T. Vodak, J. Kim, M. O'Keeffe, O.M. Yaghi, Science 300, 1127 (2003)

33. C.M. Brown, Y. Liu, T. Yildirim, V.K. Peterson, C.J. Kepert, Nanotechnology 20(20), 204025 (2009)

34. J.M. Nicol, J. Eckert, J. Howard, J. Phys. Chem. 92(25), 7117 (1988)

35. A.J. Ramirez-Cuesta, P.C.H. Mitchell, D.K. Ross, P.A. Georgiev, P.A. Anderson, H.W. Langmi, D. Book, J. Mater. Chem. 17, 2533 (2007)

36. G.J. Kubas, Chem. Rev. 107(10), 4152 (2007)

37. H. Jobic, J. Kärger, M. Bée, Phys. Rev. Lett. 82, 4260 (1999)

38. F. Fernandez-Alonso, F.J. Bermejo, C. Cabrillo, R.O. Loutfy, V. Leon, M.L. Saboungi, Phys. Rev. Lett. 98, 215503 (2007)

39. E. Pantatosaki, H. Jobic, D.I. Kolokolov, S. Karmakar, R. Biniwale, G.K. Papadopoulos, J. Chem. Phys. 138, 034706 (2013)

40. S.A. FitzGerald, C.J. Pierce, J.L.C. Rowsell, E.D. Bloch, J.A. Mason, J. Am. Chem. Soc. 135(25), 9458 (2013)

41. J. Teufel, H. Oh, M. Hirscher, M. Wahiduzzaman, L. Zhechkov, A. Kuc, T. Heine, D. Denysenko, D. Volkmer, Adv. Mater. 25(4), 635 (2013)

42. H. Oh, I. Savchenko, A. Mavrandonakis, T. Heine, M. Hirscher, ACS Nano 8(1), 761 (2014)

43. M. Dinca, W.S. Han, Y. Liu, A. Dailly, C.M. Brown, J.R. Long, J. Am. Chem. Soc. 128(51), 16876 (2006)

44. Y. Liu, H. Kabbour, C.M. Brown, D.A. Neumann, C.C. Ahn, Langmuir 24(9), 4772 (2008) 
45. X. Lin, I. Telepeni, A.J. Blake, A. Dailly, C.M. Brown, J. Simmons, M. Zoppi, G.S. Walker, K.M. Thomas, T.J. Mays, P. Hubberstey, N.R. Champness, M. Schroder, J. Am. Chem. Soc. 131(6), 2159 (2009)

46. V.K. Peterson, C.M. Brown, Y. Liu, C.J. Kepert, J. Phys. Chem. C 115(17), 8851 (2011)

47. W.L. Queen, E.D. Bloch, C.M. Brown, M.R. Hudson, J.A. Mason, L.J. Murray, A.J. Ramirez-Cuesta, V.K. Peterson, J.R. Long, Dalton Trans. 41(14), 4180 (2012)

48. M.T. Weller, P.F. Henry, V.P. Ting, C.C. Wilson, Chem. Commun. 2009, 2973 (2009).doi:10.1039/B821336D

49. M. Kapelewski, S. Geier, M.R. Hudson, D. Stuck, J. Mason, J. Nelson, D. Xiao, Z. Hulvey, E. Gilmour, S. Fitzgerald, M. HeadGordon, C.M. Brown, J.R. Long, J. Am. Chem. Soc. 136(34), 12119 (2014)

50. T. Hofmann, P. Kumar, M. Enderle, D. Wallacher, Phys. Rev. Lett. 110, 065505 (2013)

51. V.P. Ting, A.J. Ramirez-Cuesta, N. Bimbo, J.E. Sharpe, A. Noguera-Diaz, V. Presser, S. Rudic, T.J. Mays, ACS Nano 9(8), 8249 (2015)

52. S.J.L. Billinge, M.G. Kanatzidis, Chem. Commun. 2004, 749 (2004).doi:10.1039/B309577K

53. K. Page, C.E. White, E.G. Estell, R.B. Neder, A. Llobet, T. Proffen, J. Appl. Cryst. 44, 532 (2011)

54. M.D. Foster, K.F. Jensen, Carbon 29(2), 271 (1991)

55. D. Fairen-Jimenez, F. Carrasco-Marın, D. Djurado, F. Bley, F. Ehrburger-Dolle, C. Moreno-Castilla, J. Phys. Chem. B 110(17), 8681 (2006)

56. G. Laudisio, R.K. Dash, J.P. Singer, G. Yushin, Y. Gogotsi, J.E. Fischer, Langmuir 22(21), 8945 (2006)

57. A. Malek, S. Farooq, AIChE J. 42(11), 3191 (1996)

58. P. Bénard, R. Chahine, Int. J. Hydrog. Energy 26(8), 849 (2001)

59. M.A. Richard, P. Bénard, R. Chahine, Adsorption 15(1), 43 (2009)

60. E. Dundar, R. Zacharia, R. Chahine, P. Bénard, Sep. Purif. Technol. 135, 229 (2014)

61. J. Purewal, D. Liu, A. Sudik, M. Veenstra, J. Yang, S. Maurer, U. Müller, D.J. Siegel, J. Phys. Chem. C 116(38), 20199 (2012)

62. B. Hardy, C. Corgnale, R. Chahine, M.-A. Richard, S. Garrison, D. Tamburello, D. Cossement, D. Anton, Int. J. Hydrog. Energy 37(7), 5691 (2012)

63. J. Xiao, M. Hu, P. Bénard, R. Chahine, Int. J. Hydrog. Energy 38(29), 13000 (2013)

64. C. Corgnale, B. Hardy, R. Chahine, D. Cossement, D. Tamburello, D. Anton, Int. J. Hydrog. Energy 39(30), 17083 (2014)

65. A.F. Kloutse, R. Zacharia, D. Cossement, R. Chahine, R. Balderas-Xicohténcatl, H. Oh, B. Streppel, M. Schlichtenmayer, M. Hirscher, Appl. Phys. A 121(4), 1417 (2015)

66. S. Ubaid, J. Xiao, R. Zacharia, R. Chahine, P. Bénard, Int. J. Hydrog. Energy 39(22), 11651 (2014)

67. S. Ubaid, R. Zacharia, J.-S. Xiao, R. Chahine, P. Benard, P. Tessier, Int. J. Hydrog. Energy 40(30), 9314 (2015)

68. D.D. Do, Adsorption Analysis: Equilibria and Kinetics (Imperial College Press, London, 1998)

69. J. Tóth, Adv. Colloid Interface Sci. 55, 1 (1995)

70. J.M. Honig, L.H. Reyerson, J. Phys. Chem. 56(1), 140 (1952)

71. A.A. Shapiro, E.H. Stenby, J. Colloid Interface Sci. 201(2), 146 (1998)

72. M.M. Dubinin, Pure Appl. Chem. 61(11), 1841 (1989)

73. E. Dundar, R. Zacharia, R. Chahine, P. Bénard, Fluid Phase Equilibr. 363, 74 (2014)

74. W. Zhou, H. Wu, M.R. Hartman, T. Yildirim, J. Phys. Chem. C 111(44), 16131 (2007)

75. M.-A. Richard, D. Cossement, P.-A. Chandonia, R. Chahine, D. Mori, K. Hirose, AIChE J. 55(11), 2985 (2009)
76. D. Nicholson, N.G. Parsonage, Computer Simulation and the Statistical Mechanics of Adsorption (Academic Press, London, 1982)

77. T. Düren, Y.-S. Bae, R.Q. Snurr, Chem. Soc. Rev. 38, 1237 (2009)

78. R.B. Getman, Y.-S. Bae, C.E. Wilmer, R.Q. Snurr, Chem. Rev. 112(2), 703 (2012)

79. L.D. Gelb, MRS Bull. 34(8), 592 (2009)

80. M.J. Biggs, A. Buts, Mol. Simul. 32(7), 579 (2006)

81. T.X. Nguyen, N. Cohaut, J.-S. Bae, S.K. Bhatia, Langmuir 24(15), 7912 (2008)

82. J.C. Palmer, A. Llobet, S.-H. Yeon, J.E. Fischer, Y. Shi, Y. Gogotsi, K.E. Gubbins, Carbon 48(4), 1116 (2010)

83. L.J. Abbott, K.E. Hart, C.M. Colina, Theor. Chem. Acc. 132(3), 1334 (2013)

84. A. Gonciaruk, F.R. Siperstein, Carbon 88, 185 (2015)

85. V. Buch, J. Chem. Phys. 100, 7610 (1994)

86. F. Darkrim, D. Levesque, J. Chem. Phys. 109, 4981 (1998)

87. G. Garberoglio, A.I. Skoulidas, J.K. Johnson, J. Phys. Chem. B 109(27), 13094 (2005)

88. J.L. Belof, A.C. Stern, B. Space, J. Chem. Theory Comput. 4(8), $1332(2008)$

89. K. McLaughlin, C.R. Cioce, J.L. Belof, B. Space, J. Chem. Phys. 136, 194302 (2012)

90. Q. Wang, J.K. Johnson, J. Chem. Phys. 110, 577 (1999)

91. M. Wahiduzzaman, C.F.J. Walther, T. Heine, J. Chem. Phys. 141, 064708 (2014)

92. R.P. Feynman, A.R. Hibbs, Quantum Mechanics and Path Integrals (McGraw-Hill, New York, 1965)

93. A.K. Rappe, C.J. Casewit, K.S. Colwell, W.A. Goddard, W.M. Skiff, J. Am. Chem. Soc. 114(25), 10024 (1992)

94. S.L. Mayo, B.D. Olafson, W.A. Goddard, J. Phys. Chem. 94(26), 8897 (1990)

95. W.L. Jorgensen, D.S. Maxwell, J. Tirado-Rives, J. Am. Chem. Soc. 118(45), 11225 (1996)

96. M. Fischer, J.R.B. Gomes, M. Jorge, Mol. Simul. 40(7-9), 537 (2014)

97. R.S. Mulliken, J. Chem. Phys. 23, 1833 (1955)

98. F.L. Hirshfeld, Theor. Chim. Acta 44(2), 129 (1977)

99. C.M. Breneman, K.B. Wiberg, J. Comput. Chem. 11(3), 361 (1990)

100. P. Cieplak, W.D. Cornell, C. Bayly, P.A. Kollman, J. Comput. Chem. 16(11), 1357 (1995)

101. C. Campañá, B. Mussard, T.K. Woo, J. Chem. Theory Comput. 5(10), 2866 (2009)

102. A. Gabrieli, M. Sant, P. Demontis, G.B. Suffritti, J. Chem. Theory Comput. 11(8), 3829 (2015)

103. T.A. Manz, D.S. Sholl, J. Chem. Theory Comput. 6(8), 2455 (2010)

104. T.A. Manz, D.S. Sholl, J. Chem. Theory Comput. 8(8), 2844 (2012)

105. E.S. Kadantsev, P.G. Boyd, T.D. Daff, T.K. Woo, J. Phys. Chem. Lett. 4(18), 3056 (2013)

106. T. Watanabe, T.A. Manz, D.S. Sholl, J. Phys. Chem. C 115(11), 4824 (2011)

107. H. Fang, H. Demir, P. Kamakoti, D.S. Sholl, J. Mater. Chem. A 2, 274 (2014)

108. Y. Basdogan, S. Keskin, CrystEngComm 17, 261 (2015)

109. S.O. Odoh, C.J. Cramer, D.G. Truhlar, L. Gagliardi, Chem. Rev. 115(12), 6051 (2015)

110. C. Møller, M.S. Plesset, Phys. Rev. 46(7), 618 (1934)

111. S.F. Boys, F. Bernardi, Mol. Phys. 19(4), 553 (1970)

112. W. Kohn, L.J. Sham, Phys. Rev. 140(4A), A1133 (1965)

113. R.Q. Snurr, A.T. Bell, D.N. Theodorou, J. Phys. Chem. 97(51), 13742 (1993)

114. G. Garberoglio, J. Chem. Phys. 128, 134109 (2008) 
115. M.K. Kostov, M.W. Cole, J.C. Lewis, P. Diep, J.K. Johnson, Chem. Phys. Lett. 332(1-2), 26 (2000)

116. A. Gotzias, E. Tylianakis, G. Froudakis, T. Steriotis, Microporous Mesoporous Mater. 154, 38 (2012)

117. G.Y. Gor, M. Thommes, K.A. Cychosz, A.V. Neimark, Carbon 50(4), 1583 (2012)

118. J. Jagiello, J.P. Olivier, Carbon 55, 70 (2013)

119. J. Jagiello, J.P. Olivier, Adsorption 19(2-4), 777 (2013)

120. A. Schneemann, V. Bon, I. Schwedler, I. Senkovska, S. Kaskel, R.A. Fischer, Chem. Soc. Rev. 43, 6062 (2014)

121. S. Duane, A. Kennedy, B.J. Pendleton, D. Roweth, Phys. Lett. B 195(2), 216 (1987)

122. S. Chempath, L.A. Clark, R.Q. Snurr, J. Chem. Phys. 118, 7635 (2003)

123. D. Dubbeldam, S. Calero, D.E. Ellis, R.Q. Snurr, Mol. Simul. 42(2), 81 (2016)

124. F.-X. Coudert, A.H. Fuchs, Coord. Chem. Rev. 307(2), 211 (2016)

125. D.W. Lewis, A.R. Ruiz-Salvador, A. Gómez, L.M. RodriguezAlbelo, F.-X. Coudert, B. Slater, A.K. Cheetham, C. MellotDraznieks, CrystEngComm 11, 2272 (2009)

126. L.-C. Lin, A.H. Berger, R.L. Martin, J. Kim, J.A. Swisher, K. Jariwala, C.H. Rycroft, A.S. Bhown, M.W. Deen, M. Haranczyk, B. Smit, Nat. Mater. 11(7), 633 (2012)

127. C.E. Wilmer, M. Leaf, C.Y. Lee, O.K. Farha, B.G. Hauser, J.T. Hupp, R.Q. Snurr, Nat. Chem. 4(2), 83 (2012)

128. S. Bureekaew, R. Schmid, CrystEngComm 15, 1551 (2013)

129. Y.J. Colón, D. Fairen-Jimenez, C.E. Wilmer, R.Q. Snurr, J. Phys. Chem. C 118(10), 5383 (2014)

130. J. Goldsmith, A.G. Wong-Foy, M.J. Cafarella, D.J. Siegel, Chem. Mater. 25(16), 3373 (2013)

131. D. Anton, Hydrogen Storage Engineering Center of Excellence, 2015 DOE Annual Merit Review Proceedings. http://www. hydrogen.energy.gov/pdfs/review15/st004_anton_2015_o.pdf. Accessed 4 Jan 2016

132. S. McWhorter, G. Ordaz, Onboard Type IV Compressed Hydrogen Storage Systems-Current Performance and Cost, DOE Fuel Cell Technologies Office Record No. 13010 (2013). http://hydrogen.energy.gov/pdfs/13010_onboard_storage_perfor mance_cost.pdf. Accessed 4 Jan 2016

133. H.W. Langmi, D. Book, A. Walton, S.R. Johnson, M.M. AlMamouri, J.D. Speight, P.P. Edwards, I.R. Harris, P.A. Anderson, J. Alloys Compd. 404-406, 637 (2005)

134. Y. Yürüm, A. Taralp, T.N. Veziroglu, Int. J. Hydrog. Energy 34(9), 3784 (2009)

135. V. Presser, M. Heon, Y. Gogotsi, Adv. Funct. Mater. 21(5), 810 (2011)

136. J. Wang, S. Kaskel, J. Mater. Chem. 22, 23710 (2012)

137. K.M. Thomas, Dalton Trans. 2009, 1487 (2009).doi:10.1039/ B $815583 \mathrm{~F}$

138. M. Schlichtenmayer, M. Hirscher, J. Mater. Chem. 22, 10134 (2012)

139. H.W. Langmi, J. Ren, B. North, M. Mathe, D. Bessarabov, Electrochim. Acta 128, 368 (2014)

140. R. Dawson, A.I. Cooper, D.J. Adams, Prog. Polym. Sci. 37(4), $530(2012)$

141. Z. Xiang, D. Cao, J. Mater. Chem. A 1, 2691 (2013)

142. M. Hirscher, B. Panella, B. Schmitz, Microporous Mesoporous Mater. 129(3), 335 (2010)

143. H. Furukawa, M.A. Miller, O.M. Yaghi, J. Mater. Chem. 17, 3197 (2007)

144. H. Furukawa, N. Ko, Y.B. Go, N. Aratani, S.B. Choi, E. Choi, A.Ö. Yazaydin, R.Q. Snurr, M. O'Keeffe, J. Kim, O.M. Yaghi, Science 329, 424 (2010)

145. S. Furukawa, J. Reboul, S. Diring, K. Sumida, S. Kitagawa, Chem. Soc. Rev. 43, 5700 (2014)
146. H.-L. Jiang, T.A. Makal, H.-C. Zhou, Coord. Chem. Rev. 257(15-16), 2232 (2013)

147. S.K. Bhatia, A.L. Myers, Langmuir 22(4), 1688 (2006)

148. Y.-S. Bae, R.Q. Snurr, Microporous Mesoporous Mater. 132(1-2), 300 (2010)

149. M. Schlichtenmayer, B. Streppel, M. Hirscher, Int. J. Hydrog Energy 36(1), 586 (2011)

150. S. Tedds, A. Walton, D.P. Broom, D. Book, Faraday Discuss. 151, 75 (2011)

151. M. Bastos-Neto, C. Patzschke, M. Lange, J. Möllmer, A. Möller, S. Fichtner, C. Schrage, D. Lässig, J. Lincke, R. Staudt, H. Krautscheid, R. Gläser, Energy Environ. Sci. 5, 8294 (2012)

152. D.P. Broom, D. Book, in Advances in Hydrogen Production, Storage and Distribution, ed. by A. Basile, A. Iulianelli (Woodhead Publishing, Cambridge, 2014), p. 410

153. M. Schlichtenmayer, M. Hirscher, Appl. Phys. A. (2016 in press)

154. T. Pham, K.A. Forrest, R. Banerjee, G. Orcajo, J. Eckert, B. Space, J. Phys. Chem. C 119(2), 1078 (2015)

155. M.H. Rosnes, M. Opitz, M. Frontzek, W. Lohstroh, J.P. Embs, P.A. Georgiev, P.D.C. Dietzel, J. Mater. Chem. A 3, 4827 (2015)

156. R. Babarao, M. Eddaoudi, J.W. Jiang, Langmuir 26(13), 11196 (2010)

157. F. Nouar, J. Eckert, J.F. Eubank, P. Forster, M. Eddaoudi, J. Am. Chem. Soc. 131(8), 2864 (2009)

158. P.A. Szilágyi, I. Weinrauch, H. Oh, M. Hirscher, J. Juan-Acañiz, P. Serra-Crespo, M. de Respinis, B.J. Trześniewski, F. Kapteijn, H. Geerlings, J. Gascon, B. Dam, A. Grzech, R. van de Krol, J. Phys. Chem. C 118(34), 19572 (2014)

159. S. Barman, A. Khutia, R. Koitz, O. Blacque, H. Furukawa, M. Iannuzzi, O.M. Yaghi, C. Janiak, J. Hutter, H. Berke, J. Mater. Chem. A 2, 18823 (2014)

160. T. Pham, K.A. Forrest, P. Nugent, Y. Belmabkhout, R. Luebke, M. Eddaoudi, M.J. Zaworotko, B. Space, J. Phys. Chem. C 117(18), 9340 (2013)

161. H. Furukawa, U. Müller, O.M. Yaghi, Angew. Chem. Int. Ed. 54(11), 3417 (2015)

162. S.M. Cohen, Chem. Rev. 112(2), 970 (2012)

163. P. Deria, J.E. Mondloch, O. Karagiaridi, W. Bury, J.T. Hupp, O.K. Farha, Chem. Soc. Rev. 43, 5896 (2014)

164. C.V. McGuire, R.S. Forgan, Chem. Commun. 51, 5199 (2015)

165. N.B. McKeown, J. Mater. Chem. 20, 10588 (2010)

166. M. Mastalerz, Chem. Eur. J. 18(33), 10082 (2012)

167. J. Tian, P.K. Thallapally, B.P. McGrail, CrystEngComm 14, 1909 (2012)

168. G. Zhang, M. Mastalerz, Chem. Soc. Rev. 43, 1934 (2014)

169. G. Zhang, O. Presly, F. White, I.M. Oppel, M. Mastalerz, Angew. Chem. Int. Ed. 53(6), 1516 (2014)

170. A.I. Cooper, Angew. Chem. Int. Ed. 51(32), 7892 (2012)

171. X. Zhao, B. Xiao, A.J. Fletcher, K.M. Thomas, D. Bradshaw, M.J. Rosseinsky, Science 306, 1012 (2004)

172. A.J. Fletcher, K.M. Thomas, M.J. Rosseinsky, J. Solid State Chem. 178(8), 2491 (2005)

173. H.-J. Choi, M. Dincă, J.R. Long, J. Am. Chem. Soc. 130(25), $7848(2008)$

174. S. Hiroke, S. Shimomura, S. Kitagawa, Nat. Chem. 1(9), 695 (2009)

175. H.J. Park, M.P. Suh, Chem. Commun. 46, 610 (2010)

176. J.A. Mason, J. Oktawiec, M.K. Taylor, M.R. Hudson, J. Rodriguez, J.E. Bachman, M.I. Gonzalez, A. Cervellino, A. Guagliardi, C.M. Brown, P.L. Llewellyn, N. Masciocchi, J.R. Long, Nature 527, 357 (2015)

177. X. Song, T.K. Kim, H. Kim, D. Kim, S. Jeong, H.R. Moon, M.S. Lah, Chem. Mater. 24(15), 3065 (2012) 
178. H. Ma, B. Li, L. Zhang, D. Han, G. Zhu, J. Mater. Chem. A 3, 19346 (2015)

179. N. Stetson, G. Ordaz, J. Adams, K. Randolph, S. McWhorter, J. Alloys Compd. 580, S333 (2013)

180. U. S. DRIVE Partnership, 2015, http://energy.gov/sites/prod/ files/2015/05/f22/fcto_targets_onboard_hydro_storage_explana tion.pdf. Accessed 29 Nov 2015

181. B. Schmitz, U. Müller, N. Trukhan, M. Schubert, G. Férey, M. Hirscher, ChemPhysChem 9(15), 2181 (2008)

182. Y. Ming, J. Purewal, D. Liu, A. Sudik, C. Xu, J. Yang, M. Veenstra, K. Rhodes, R. Soltis, J. Warner, M. Gaab, U. Müller, D.J. Siegel, Microporous Mesoporous Mater. 185, 235 (2014)

183. R. Zacharia, D. Cossement, L. Lafi, R. Chahine, J. Mater. Chem. 20, 2145 (2010)

184. Y. Ming, H. Chi, R. Blaser, C. Xu, J. Yang, M. Veenstra, M. Gaab, U. Müller, C. Uher, D.J. Siegel, Int. J. Heat Mass Transf. 82, 250 (2015)

185. R.K. Ahluwalia, J.-K. Peng, T.Q. Hua, Int. J. Hydrog. Energy 40(19), 6373 (2015)

186. A. Chakraborty, S. Kumar, Int. J. Hydrog. Energy 38(10), 3973 (2013)

187. B.L. Huang, Z. Ni, A. Millward, A.J.H. McGaughey, C. Uher, M. Kaviany, O. Yaghi, Int. J. Heat Mass Transf. 50(3-4), 405 (2007)
188. C. Schlemminger, E. Naess, U. Bunger, Int. J. Hydrog. Energy 40(20), 6606 (2015)

189. L. Han, M. Budge, P.A. Greaney, Comput. Mater. Sci. 94, 292 (2014)

190. J. Ren, T. Segakweng, H.W. Langmi, B.C. North, M. Mathe, J. Alloys Compd. 645, S170 (2015)

191. D. Liu, J.J. Purewal, J. Yang, A. Sudik, S. Maurer, U. Mueller, J. Ni, D.J. Siegel, Int. J. Hydrog. Energy 37(7), 6109 (2012)

192. I.I. Fedchenia, B.A. van Hassel, R. Brown, Inverse Probl. Sci. Eng. 23(3), 425 (2015)

193. A. Chaise, P. de Rango, P. Marty, D. Fruchart, S. Miraglia, R. Olivès, S. Garrier, Int. J. Hydrog. Energy 34(20), 8589 (2009)

194. H. Leung, U.S. Patent 9736819 A1 19971009, Apparatus and methods for storing and releasing hydrogen (1997)

195. R. Wegeng, S. Rassat, W. Tegrotenhuis, K. Drost, V. Vishwanathan, U. S. Patent 20020194990 A1 20021226, Method and apparatus for thermal swing adsorption and thermally-enhanced pressure swing adsorption (2002)

196. D. Anton, Hydrogen Storage Engineering Center of Excellence (HSECoE), DOE Hydrogen and Fuel Cells Program, FY 2012 Annual Progress Report. http://www.hydrogen.energy.gov/pdfs/ progress12/iv_d_1_anton_2012.pdf. Accessed 29 Nov 2015

197. A.G. Slater, A.I. Cooper, Science 348, aa8075 (2015) 